Arqueología y Sociedad,

№ 22, 2010

\title{
TUMBAS DE GUERREROS CHACHAPOYA EN ABRIGOS ROCOSOS DE LA PROVINCIA DE LUYA, DEPARTAMENTO DE AMAZONAS
}

Klaus Koschmieder ${ }^{i}$

Catherine Gaitherii

\begin{abstract}
Resumen
Los cronistas españoles describieron a los Chachapoya como una confederación de varios subgrupos organizados en curacazgos de variable complejidad y tamaño. Compartían numerosos rasgos en su arquitectura y cultura material, pero ligeras diferencias en la iconografía y en las prácticas funerarias a nivel interregional podrían ser reminiscencias a los origenes y tradiciones de los distintos subgrupos, los cuales migraron hace más de mil años hacia la casi despoblada zona al este del río Marañon. La tradición oral transmitida a los españoles nos informa acerca de la organización dual de los curacazgos Chachapoya: El poder fue repartido entre dos curacas, uno con poder político y representante del culto y el otro estrechamente ligado con asuntos bélicosos. Los Chachapoya tenían fama de ser valientes guerreros que practicaban la caza de cabezas trofeo.

Durante nuestras investigaciones arqueológicas en abrigos rocosos de la provincia de Luya (2007) fueron localizadas varias tumbas de presuntos guerreros Chachapoya, asociadas con pinturas rupestres, que demuestran la presencia de estos guerreros con sus armas y la práctica de la caza de cabezas trofeo. Los hombres fueron enterrados con un ajuar funerario variado y muestran fracturas en varias partes del cuerpo, especialmente en el cráneo (trepanación). Las pinturas rupestres y la presencia de objetos "tardíos" comprueban que la caza de cabezas trofeo continuó hasta la época Colonial Temprano.
\end{abstract}

Palabras clave

Chachapoya, curacazgos, cabezas trofeo, abrigos rocosos, pinturas rupestres, trepanación.

\begin{abstract}
Spanish chroniclers described the Chachapoya as a confederation of several subgroups, organized into chiefdoms of varying size and complexity. They shared many features in their architecture and material culture, but slight differences in the iconography and funerary practices at the interregional level could be reminiscent of the origins and traditions of the different subgroups, which migrated over a thousand years ago to the almost uninhabited area east of the Rio Marañon. The oral tradition transmitted to the Spanish informs us of the dual organization of Chachapoya chiefdoms: The power was divided between two chiefs, one with political power and representative of the cult, and the other closely linked with military affairs. The Chachapoya were known as brave warriors who practiced trophy head-hunting.
\end{abstract}

i Comunidad Alemana de Investigaciones (DFG), Bonn, Alemania.

Correo electrónico: rockydog@web.de

ii Departmento of Antropología, Metropolitan State College of Denver, Estados Unidos.

Correo electrónico: gaither2@comcast.net 
During archaeological research in rock shelters in the province of Luya (2007) several graves of presumed Chachapoya warriors were located associated with cave paintings, which depict these warriors with their weapons and the practice of trophy head-hunting. The men were buried with varied grave goods and demonstrate fractures in various parts of the body, but especially in the skull (including trepanations). The cave paintings and the presence of "late" objects indicate that the hunting of trophy heads continued until the early colonial period.

\section{Keywords}

Chachapoya, chiefdoms, trophy heads, rock shelters, cave paintings, trepanation.

\section{INTRODUCCIÓN}

Al parecer las formas de enterramiento de los Chachapoya fueron las más diversas en todo el área andina y dejan suponer que hubo varios subgrupos con diferentes tradiciones funerarias. También indican que hubo diferentes grupos sociales en las sociedades ${ }^{1}$ Chachapoya. Lamentablemente la mayoría de los investigadores reporta solamente las dos prácticas funerarias más espectaculares, las chullpas y los sarcófagos de apariencia antropomorfa (purunmachos) (ver p.e. v. Hagen 2002, 2005; Kauffmann/Ligabue 2003). Sobre todo los sarcófagos fueron interpretados como la última morada de los curacas, guerreros o de la élite Chachapoya,

"Ésta era una forma emblemática de sepulcro, destinada a inhumar tan sólo a los difuntos de alta jerarquía”. (Kauffmann/Ligabue 2003: 205)

pero hay que resaltar que en su gran mayoría los mausoleos y sarcófagos de la provincia de Luya, con la excepción de pocos sitios (p.e. Karajía), contienen los restos mortales de gente común, entre ellos hombres, mujeres, niños, bebés y hasta animales, acompañados con objetos sencillos como pequeños ceramios, material lítico y huesos trabajados. La forma de enterrar a las personas en sarcófagos ha sido un patrón bastante común para un subgrupo Chachapoya que ocupaba el norte de la provincia de Luya, ya que

1 En vez de hablar de étnias ó culturas preferimos utilizar términos menos problemáticos como las poblaciónes ó las sociedades Chachapoya. Aplicamos el plural, ya que en realidad varios subgrupos formaban la tradición Chachapoya. hemos podido registrar cientos de sarcófagos en un área de solamente $15 \mathrm{~km}^{2}$ al este y noreste del pueblo de Lámud. Mientras la mayoría de las chullpas contienen los restos mortales de varios individuos, los sarcófagos albergan solamente el fardo funerario de un individuo. ${ }^{2}$ Hemos podido determinar que no todos los sarcófagos cónicos contienen entierros primarios en posición fetal, ya que en algunas de las cápsulas de piedra y barro se encontraron "paquetes" de huesos amarrados con soguillas de fibra vegetal. Obviamente en algún momento los muertos fueron exhumados, como hemos podido comprobar en tumbas vacías de un patio ceremonial de Kacta - PAJ $237,{ }^{3}$ y trasladados a unos acantilados cercanos (San Antonio), donde encontraron su última morada en unos sarcófagos antropomorfos.

Otras prácticas funerarias de los Chachapoya incluyen entierros simples debajo de piedras amontonadas o rocas en la base de los acantilados y en las faldas de los cerros (Koschmieder 2008), debajo de los pisos de las viviendas circulares u ovaladas (Gaither et al. 2008; Koschmieder 2008; Narváez 1996 b; Ruiz 2009 a; Zetzsche/Koschmieder 2010) y en el interior de recintos semicirculares, los cuales se encuentran adosados a la roca madre de los acantilados, como los de Tingorbamba o Pueblo de los Muertos (Koschmieder 2008). Restos mortales

2 Solamente en un sitio (PAJ 62-A) encontramos un sarcófago con dos cara-máscaras, el cuál contenía los restos de dos individuos.

3 La abreviatura PAJ significa Proyecto Arqueológico Jucusbamba y los números correlativos corresponden a los sitios registrados sucesivamente durante el trabajo de prospección (2007-2009). 
se hallaron también en los muros de contención de algunas terrazas agrícolas (Lerche 1986: 136) y en varios nichos del muro perimétrico del asentamiento fortificado de Kuelap (Bandelier 1940; Langlois 1934; Middendorf 1895; Narváez 1988: 118).

Las investigaciones arqueológicas en abrigos rocosos (Koschmieder 2008) y en cuevas (machay) son novedosas y escasas (Briceño/ Muscutt 2004; Fabre 2008; Fabre et al. 2008; Koschmieder 2008; Lerche 1986, 1995: 67-75), pero demuestran que el mundo (semi)subterráneo fue también utilizado por las poblaciones de tradición Chachapoya como lugar de entierro.

El presente artículo tiene como objetivo principal presentar los resultados de nuestras investigaciones arqueológicas en abrigos rocosos de la provincia de Luya durante el año 2007. Los dos ejemplos que vamos a presentar (PAJ 56-B y PAJ 113) comprueban, que especialmente los abrigos rocosos fueron escogidos por un subgrupo Chachapoya para enterrar personas de alto rango.

Para su clasificación cronológica nos parece importante mencionar, que la mayoría de los sitios funerarios Chachapoya, los cuales se ubican en los acantilados (p.e. estructuras semicirculares, cuevas, abrigos rocosos, chullpas y sarcófagos), están directamente asociados a pinturas rupestres, mayormente de color rojo ocre.

\section{Los Chachapoya}

\subsection{Información general}

Chachapoya es el término genérico para un gran número de subgrupos, cuyos nombres originales en la mayoría de los casos se han perdido. ${ }^{4} \mathrm{Su}$ orígen y su significado es incierto, pero es posible que los Inca dieron el nombre (Chachapoya) a todos los autóctonos, con propósitos administrativos, reuniendo así los diferentes curacaz-

4 Espinoza (1967: 232) menciona, en base a la declaración de Juan López Velazco, hasta 22 subgrupos Chachapoya, pero el mismo se da cuenta que los grupos más importantes, como los Chillao(s), los Chilcho(s) o los Paclla no aparecen en la lista de López. gos en una sola unidad (Schjellerup 2005: 59). Mientras Blas Valera lo interpretaba como "lugar de varones fuertes" (Garcilaso 1965 [1609], lib. VIII, cap. I: 291), otro autor lo deriva de sachapullo "que quiere decir monte de nubes..." (Lecuanda 1861 [1792]). Según el alemán Middendorf (1895: 233) la palabra proviene del aimara y podria significar "nubes de hombres" o "hombres de las nubes", refiriéndose a la actitud guerrera o al espacio geográfico que ocupaban los Chachapoya. ${ }^{5}$

La "cultura arqueológica" Chachapoya se desarrolló entre 800 y 1470 D.C. en la ceja de selva (Bonavía/Ravines 1976) de la sierra nororiental del Perú. Se reconoce el espacio geográfico que ocupaban los subgrupos Chachapoya en base a la distribución de sus restos arquitectónicos abandonados. Abarca el actual departamento de Amazonas así como algunas partes de La Libertad y San Martín. La barrera natural occidental constituyó el Río Marañon, mientras los otros límites podrian ubicarse en las zonas de Pías (sur), Bagua (norte) y cerca de los ríos Huallaga y Huayabamba en el este (Kauffmann/Ligabue 2003: 21-25; Lerche 1995: 21; Schjellerup 205: 53-55). Al momento de la llegada de los españoles unos trecientos mil a medio millón de Chachapoya poblaron esta área geográfica (Lerche 1986: 71-73; 1995: 36). La mayoría de sus asentamientos se ubican en la cuenca del río Utcubamba.

En general se postula que a partir del 800 d.C. unos migrantes llegaron hacia la casi despoblada zona al este del Río Marañon (Kauffmann/Ligabue 2003; Lerche 1986: 57; Savoy 1970: 131-143). Para Kauffmann la presencia de chullpas en el área Chachapoya es decisivo para asignarles un origen serrano ("serranización de la selva"). ${ }^{6}$ Según este autor los recién llega-

5 El término quechua puyu también significa nubes, así que la relación con el espacio geográfico que ocupaban los Chachapoya es obvia.

6 Es cierto que la tradición de construir chullpas empieza durante el Horizonte Medio, pero hay que tener en cuenta que prácticamente todas las chullpas Chachapoya fueron construidas en tiempos más tardíos (Intermedio Tardío hasta el Horizonte Tardío). Hasta el momento no existen fechados de radiocarbono que comprueban construcciones más antiguas. 
dos abandonaron su tierra natal a causa de una presión demográfica y en consecuencia por la falta de recursos naturales (Kauffmann/Ligabue 2003: 27, 39, 111, 122).

Otros autores piensan que la tradición cultural Chachapoya se desarrolló a nivel local o regional (p.e. v. Hagen 2002: 49; Ruiz 2009 a: $5)$, pero a pesar de las "evidencias" recogidas (p.e. cerámica diagnóstica) en zonas como Bagua (Shady 1976, 1992) ${ }^{7}$ o en el parque del Abiseo (Church 1991, 1994) queda un obvio vacío de 1000 a 2000 años en los registros cronológicos (ver Lerche 1995: 23-24) que no explican los defensores de esta hipótesis. No existen testimonios que señalen un gradual desarrollo a partir de tiempos bien tempranos (Precerámico o Formativo) hasta la aparición de la tradición Chachapoya (aprox. 800-1500 d.C.).

Otros investigadores no dan su opinión sobre el posible orígen de la tradición Chachapoya, pero algunos rasgos arqueológicos dejan suponer que los diferentes subgrupos migraron de la selva baja hacia la "ceja de selva". Entre otros podríamos mencionar la construcción de recintos circulares u ovalados con techo cónico de paja (no muy común para la sierra norte), la costumbre de enterrar los muertos en las viviendas durante su uso y la caza de cabezas trofeo. Conflictos bélicosos entre los diferentes subgrupos Chachapoya fueron comunes, como demuestra la gran cantidad de restos óseos con fracturas y trepanaciones encontrados hasta la fecha. Posiblemente se trataba de diferentes grupos lingüisticos (y/ó étnicos?) los cuales desde el inicio del movimiento migratorio se encontraban en conflictos permanentes. Varios autores postulaban una afiliación lingüistica estrecha entre la selva baja y la "ceja de selva" (Rivet 1949; Zevallos 1966: 28). El lingüista Torero (1989: 238), remitiendose a la toponomía y onomástica de la zona, postula un idioma Chachapoya y establece posibles vínculos con la lengua Jivaro. Según los

7 R. Shady y R. Ravines indican que algunos estilos de cerámica, registrados por ellos, tendrian una "clara filiación amazónica" (Shady 1992: 29) o "un cercano parentesco con ciertos tipos de alfarería de las tierras bajas del Amazonas" (Ravines 1972: 218). estudiosos Taylor (1996) y Zevallos (1982) habian sido los Inca quienes introdujeron el quechua entre los Chachapoya.

\subsection{Las evidencias (etno-) históricas}

Los cronistas españoles prestaban poca atención a los Chachapoya y propagaban muchos clichés, especialmente acerca de sus aspectos físicos:

"Son estos indios naturales de los Chachapoyas los más blancos y agraciados de todos cuantos yo he visto en las Indias que he andado: y sus mugeres fueron tan hermosas...: porque son blancas y muchas muy dispuestas." (Cieza 1984 [1553], I: 229)

También mencionan algunas vestimentas, tocados y adornos corporales (Calancha 1976 [1638], III: 866; Cieza 1984 [1553], I: 229-230; Garcilaso 1965 [1609], lib. VIII, cap. I: 291; Guamán Poma 1936 [1615]: 161).

En las fuentes coloniales los Chachapoya fueron descritos como "xente de guerra" con "las cabezas trasquiladas a partes" (Pizarro 1986 [1572]: 75), los cuales practicaban la caza de cabezas trofeo y ofrecieron una dura resistencia a la conquista Inca (Cieza 1986 [1553], II: 162, 187; Cobo 1956 [1653], II: 84; Lizárraga 1987 [1605]: 161; Murúa 2001 [1611]: 150; Salinas Loyola 1965 [1571], III: 197).

Algunos subgrupos han sido famosos por sus brujos y curanderos (Acosta 1954 [1590]: 269; Pizarro 1986 [1572]: 75; Polo de Ondegardo 1916 [1571], I: 30) que practicaban en un ambiente de abundantes plantas medicinales (Arriaga 1920 [1621]: 26).

\section{Según Blas Valera}

"Estos Chachapuyas adoraban culebras, y tenían el ave cuntur por su principal dios" (Garcilaso 1965 [1609], lib. VIII, cap. I: 291),

Calancha (1976 [1638], III: 836, 890) nos informa que también adoraban a las estrellas. Una de las huacas principales era Curichaculla, la cuál fue llevada por los Inca al Cuzco (Sarmiento de Gamboa 1965 [1572], IV: 263). 


\section{La organización política-social}

Las fuentes (etno-)históricas caracterizan la organización política-social de los Chachapoya como una confederación de diferentes curacazgos y/o ayllus/parcialidades (grupos de parentesco), las cuales tenían sus propias llaqtas (centros poblados). ${ }^{8}$ Los curacazgos actuaban en forma autónoma, pero en casos de una amenaza militar o para realizar trabajos colectivos se unieron los subgrupos (Espinoza 1967; Lerche 1995). La realización de obras monumentales (como Kuelap) y la capacidad de formar alianzas bélicas entre poblaciones, que en otras ocasiones se enfrentaban entre ellos por los reducidos recursos naturales (Cieza 1987 [1553], III: 293), dejan de suponer que hubo una tendencia hacia una macro-organización social con rasgos estatales (Lerche 1995). Un curaca principal encabezaba la sociedad estratificada, el cuál tenía que preocuparse de las actividades administrativas y del culto, mientras la denominada segunda persona dirigía las actividades bélicas. ${ }^{9}$

La presencia de varios curacazgos o subgrupos se manifiesta en primer lugar en las diferentes prácticas funerarias (chullpas en el sur y sarcófagos en el norte). Sin embargo con el tiempo los antiguos subgrupos desarrollaron un estilo casí uniforme en la arquitectura y en la cultura material, lo que deja suponer que hubo un proceso de unificación político-cultural en la tradición Chachapoya.

\section{El impacto Inca}

La tradición Chachapoya perduró hasta 1470/80 d.C. cuando su territorio fue integrado al impe-

8 La fuente clásica para el estudio de la historia de los Chachapoya es una publicación de Waldemar Espinoza (1967) con el título "Los señorios étnicos de Chachapoyas y la alianza hispano-Chacha”, en la cuál el autor presenta un documento de Diego de Vizcarra, corregidor de Cajamarquilla (1574).

9 Todo indica que el orden interno de un curacazgo Chachapoya bajo el dominio Inca era marcado por la presencia de dos curaca. No sabemos si este orden dual andino existía antes de la llegada de los Inca en el territorio Chachapoya (Lerche 1995: 38, 42). rio Inca. Las primeras operaciones militares fueron realizadas bajo el mando de Tupac Yupanqui. Varios cronistas mencionan la resistencia tenaz de los Chachapoya, pero no podían evitar la toma de sus territorios por parte de los Inca (Cieza 1986 [1553], II: 162; Cobo 1956 [1653], II: 84; Garcilaso 1965 [1609], lib. VIII, cap. II: 293; Sarmiento 1965 [1572], IV: 248-249).

Durante el dominio del siguiente Inca Huayna Capac hubieron varias rebeliones, las cuales fueron reprimidas con todo rigor (Cieza 1986 [1553], II: 187-188, Cobo 1956 [1653], II: 89; Sarmiento 1965 [1572], IV: 260). Aproximadamente un $50 \%$ de la población Chachapoya perdió la vida o fue reubicada en otras áreas (mitmaq) (Lerche 1995). Otro efecto de la conquista Inca fue la reorganización del sistema político-administrativo. Los antiguos curacazgos independientes fueron agrupados en unidades administrativas más grandes (hunos), por lo que la cantidad de curacas fue reducida (Espinoza 1967: 231, 240; v. Hagen 2002: 221; Schjellerup 2005). El sistema de herencia tradicional fue anulado por los Inca, por lo cual hubo litígios durante el tiempo de los españoles, en los cuales las antiguas familias de curacas reclamaban sus derechos (Espinoza 1967; Lerche 1995).

Los Inca construyeron centros adminsitrativos y caminos en la región e introdujeron un nuevo idioma (quechua) y una nueva religión. Las innovaciones no se manifestaban tanto en cambios materiales. Los Chachapoya seguían construyendo edificios circulares y continuaban con la producción de cerámica con su propio estilo. Más bien, los Inca integraban sus simbolos en los objetos de la tradición Chachapoya (Lerche 1995; Schjellerup 2005).

\subsection{Las evidencias arquitectónicas}

La mayoría de los asentamientos Chachapoya, algunos fortificados (Kuelap), se sitúan en la zona quichua (1800-3200 msnm), donde se encuentran los terrenos de cultivos tradicionales, como el maíz. Los cronistas españoles describieron el área geográfica como de dificil acceso, accidentado y húmedo: 
"Montañas asperas donde siempre llueve... tierras montuosa, poblada de sabandijas, abundante de tigres, llena de arboles silvestres..." (Calancha 1976 [1638]: 866).

“...tierra muy áspera y de gran humedad, que todo el año no hace sino llover, y por esta causa los indios tienen sus casas edificadas en las cumbres de las cuestas y altos..." (Los primeros Agustinos 1916 [1557]: 56).

Por lo general las denominadas llaqtas, que presentan entre 15 y 400 viviendas, se ubican encima de las mesetas y menos frecuentemente en las faldas de los cerros. Previo a la construcción de los recintos circulares u ovalados, los Chachapoya nivelaron el terreno y en otros casos construyeron terrazas artificiales con muros de contención. Algunas estructuras, las cuales muestran un díametro promedio de 4 a 8 metros, descansan sobre embasamientos (semicirculares) que presentan aleros o cornisas de lajas salientes (Narváez 1988). Las viviendas fueron cubiertas con techos cónicos de madera y paja, como demuestran estructuras habitadas hasta el siglo XX (Langlois 1939; Werthemann 1892; Wiener 1884). Algunos edificios están adornados con frisos de piedras, representando en su gran mayoría motivos en zigzag o rombos. Según el estudio de la iconografía Chachapoya el zigzag podría representar las culebras y la autoridad máxima (curaca principal), mientras los rombos fueron relacionados a los felinos y a lo bélico (segunda persona o guerrero) (Lerche 1995).

La aparente uniformidad de la arquitectura y cultura material contrasta con los esquemas funerarios diferentes. Como ya mencionamos anteriormente, las prácticas funerarias de los Chachapoya fueron bastante variados, lo que se debe a la existencia de diferentes subgrupos y a las diferentes clases sociales dentro de las sociedades Chachapoya. Resaltan mausoleos (chullpas) en el sur y sarcófagos antropomorfos (purunmachos) en el norte. En adelante presentamos los resultados de nuestras investigaciones en abrigos rocosos de la provincia de Luya, donde hemos podido documentar entierros de personajes de alto rango.
2. INVESTIGACIONES ARQUEOLÓGICAS EN ABRIGOS rocosos de la provincia de Luya (Proyecto Arqueológico Jucusbamba)

\subsection{El área de investigación}

Los dos abrigos rocosos (PAJ 56-B y PAJ 113) fueron documentados durante los trabajos de prospección (y excavación) en el año 2007. En el transcurso de esta primera temporada del "Proyecto Arqueológico Jucusbamba" registramos 182 sitios arqueológicos, los cuales se encuentran en la margen izquierda del río Utcubam$\mathrm{ba}^{10}$ y entre las siguientes coordenadas UTM: E 0176180-0179093 y N 9320104-9329056, es decir en un área de $9 \times 3 \mathrm{~km}\left(=27 \mathrm{~km}^{2}\right)$. Los sitios arqueológicos, entre ellos asentamientos con recintos circulares u ovaladas, terrazas, caminos, una gran variedad de sitios funerarios, petroglifos y pinturas rupestres, se localizaron en los acantilados, faldas y cumbres de los cerros a alturas entre 1500 y $2700 \mathrm{msnm}$.

Por lo general los sitios funerarios se encuentran en regular hasta buen estado de conservación. Solamente los sarcófagos y chullpas sufrieron mayores daños. Muchos sarcófagos se han derrumbado por los sismos y la caida de rocas durante los siglos después de su abandono o presentan aberturas en la parte frontal, evidencias de una intervención humana. No existe una huaquería organizada en la zona, pero las personas que pasan casualmente por estos sitios rompen algunos ejemplares por curiosidad, ya que piensan que podrian contener objetos de valor. A pesar de la gran cantidad de sarcófagos dañados ${ }^{11}$ existen todavía lugares (inaccesibles) donde se conservan ejemplares intactos, como p.e. en Lengache (PAJ 111) y Corralpampa (PAJ 53). En los abrigos rocosos, donde se ubican entierros importantes debajo de rocas y piedras amontonadas, no hay indicios de excavaciones clandestinas. Parece que la gente que pasaba por estos lugares (cazadores)

$10 \mathrm{Al}$ terminar la segunda temporada (2009) llegamos a registrar un total de 266 sitios arqueológicos, los cuales se ubican hacia el norte del pueblo de Lámud en una zona entre los rios Jucusbamba y Utcubamba (ver área de prospección en la Fig. 1).

11 Durante las dos temporadas de campo $(2007,2009)$ hemos podido registrar más de 200 sarcófagos. 
no se dió cuenta de la existencia de estos lugares funerarios. Al igual que las chullpas y sarcófagos, muchos abrigos rocosos están acompañados de pinturas rupestres en las rocas cercanas, mayormente de color rojo (oscuro).

\subsection{Los contextos arqueológicos}

\subsubsection{PAJ 56-B}

El sitio arqueológico PAJ 56-B (Proyecto Arqueológico Jucusbamba - No. 56-B) fue registrado durante los trabajos de prospección el dia 31 de mayo del 2007. Se ubica a unos 4 a 5 kilómetros hacia el noreste del pueblo de Lámud (Coordenadas UTM: E 0178172 y N 9323056 [Fig. 1]) a una altura de $2486 \mathrm{msnm}$. El abrigo rocoso se encuentra en la base de un acantilado ${ }^{12}$ y sirvió como lugar de enterramiento. Los entierros se distribuían a un largo de 7,5-8,0 m (NE-SO) y un ancho entre 1,0-2,0 m (NO-SE). A causa del desprendimiento de una roca grande se formó un espacio de aproximadamente $5 \mathrm{~m}^{2}$ en la parte noreste del abrigo, donde registramos dos entierros importantes, uno cubierto con piedras grandes (Entierro No. 1) y el otro debajo de una roca de forma rectangular (Entierro No. 3) (Fig. 2). ${ }^{13}$ Entre el 2 y 4 de julio del 2007 realizamos una excavación restringida para documentar los entierros. El estado de conservación del sitio fue muy bueno, ya que los restos arqueológicos se encontraban en un ambiente seco y no hubo indicios de una intervención humana (huaqueros).

\section{Entierro No. 1}

\section{El contexto arqueológico}

El primer entierro se localizó al lado de una roca plana de forma rectangular (Fig. 2 y 3). Estaba cubierto con piedras de tamaño medio y grande y un relleno de tierra marrón suelta, el cuál contenía una gran cantidad de huesos humanos dispersos, fragmentos de cerámica, óseo animal (cuy) y restos botánicos (maíz, mate). Después

12 En la cercanía del abrigo rocoso se ubican varias chullpas (PAJ 56-A y PAJ 56-C).

13 Otros dos entierros sencillos y incompletos (No. 2 y 4) registramos en la parte suroeste del abrigo. de retirar algunas piedras apareció el primer individuo que fue enterrado en cuclillas y en una posición decúbito lateral. Originalmente fue envuelto en textiles fabricados con hilos de fibra de camélidos (lana), de los cuales quedaron solamente unos fragmentos. Uno de ellos conservaba adherido un tupu de cobre de grandes dimensiones. Los textiles se encuentran bien elaborados, uno de ellos con una decoración en urdimbres complementarias que diseñaron franjas de motivos escalonados (Fig. 4).

\section{Análisis Osteológico}

El esqueleto (Entierro No. 1) perteneció a un hombre adulto, quien tenía aprox. 30-40 años cuando murió. La estatura estimada del individuo es de 164,5 $\pm 3,4 \mathrm{~cm}$. Las patologías incluyen dos huellas redondas de traumatismo parietal en el lado derecho del cráneo, probablemente productos del impacto de una porra estrellada (Fig. 5). Ambas fracturas, que miden $20 \mathrm{x} 16 \mathrm{y}$ 29 x $26 \mathrm{~mm}$, afectan a la bóveda craneal, pero muestran evidencias de un proceso de curación. La segunda fractura, que se encuentra cerca de la bulla, una parte posterior del hueso parietal, muestra roturas concéntricas irradiadas en la bóveda craneal externa, indicios que el proceso de curación no fue completado.

El segundo metacarpiano también se fracturó, pero sanó por completo como demuestran el extremo distal con la formación del callo secundario y la deformación del hueso. Patologías dentales incluyen la pérdida de los algunos molares de las mandíbulas (los alvéolos sanaron parcialmente) y evidencias de caries (la pérdida completa de algunas coronas dentales). Todos los dientes muestran un desgaste moderado hasta notable y sarro de leve a moderado.

\section{Las ofrendas}

Las ofrendas del individuo consistían en tres objetos de metal, una flauta elaborada de un caracol marino, dos cuencos de cerámica (fragmentados), un objeto de madera en forma antropomorfa y más de 100 cuentas de collar de diferentes materiales. Al retirar los primeros 


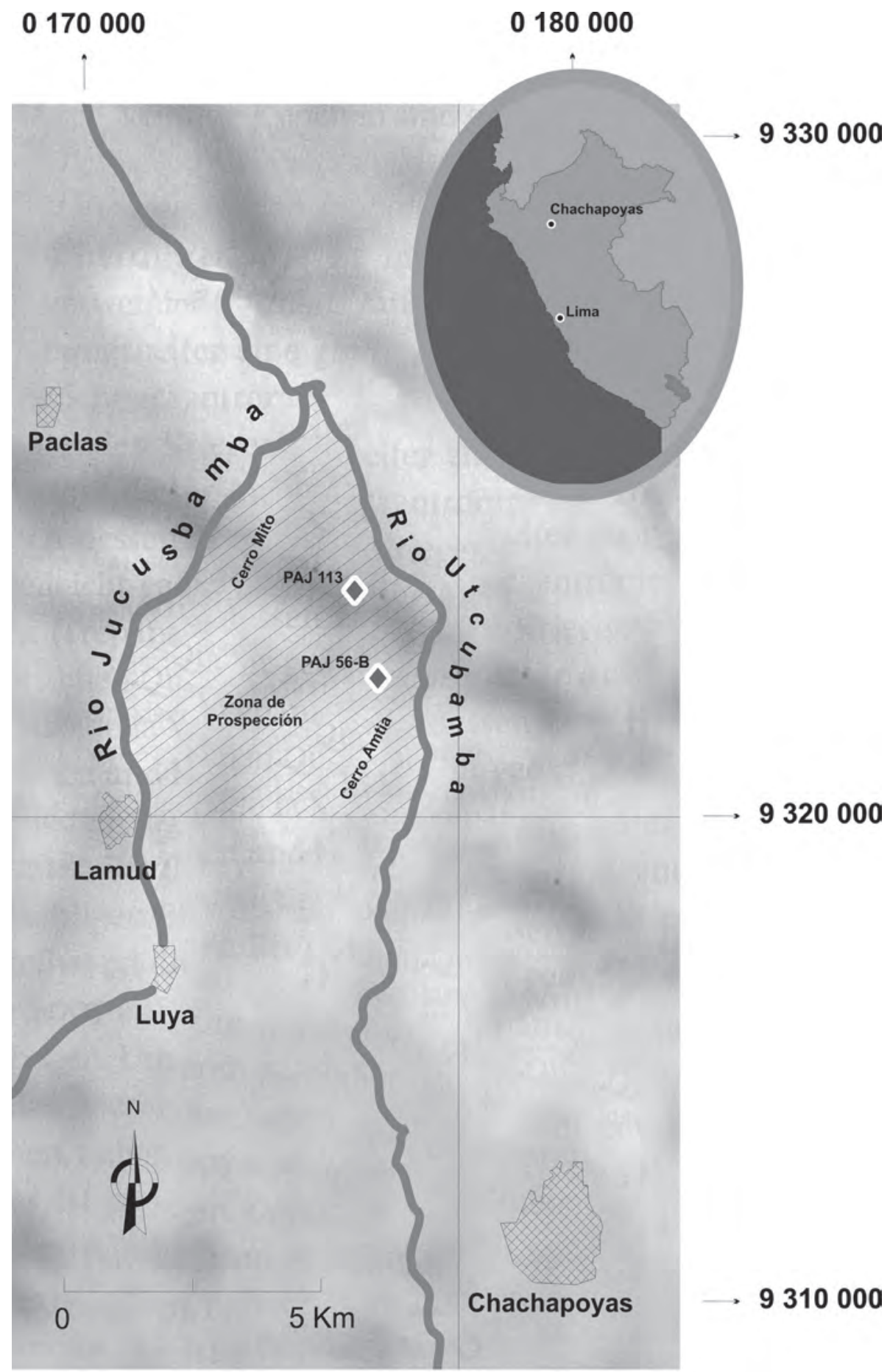

Figura 1. Mapa del área de investigación con ubicación de los abrigos rocosos PAJ 56-B y PAJ-113 (Dibujo: A. Molina). 

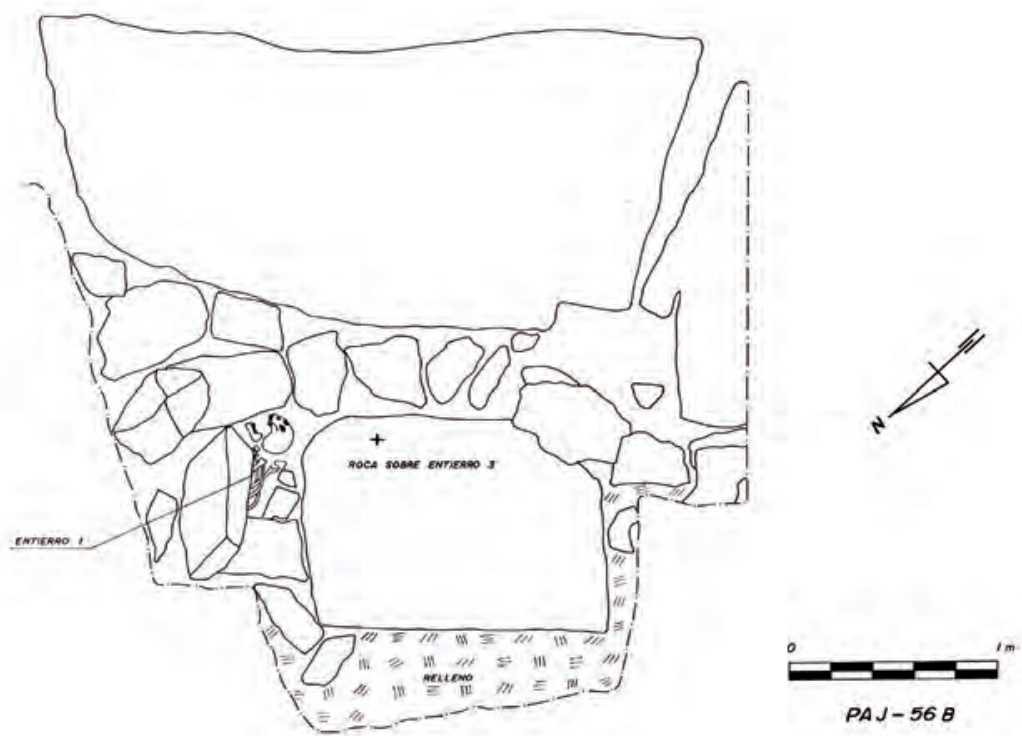

Figura 2. Mapa PAJ 56-B (Dibujo: K. Koschmieder)

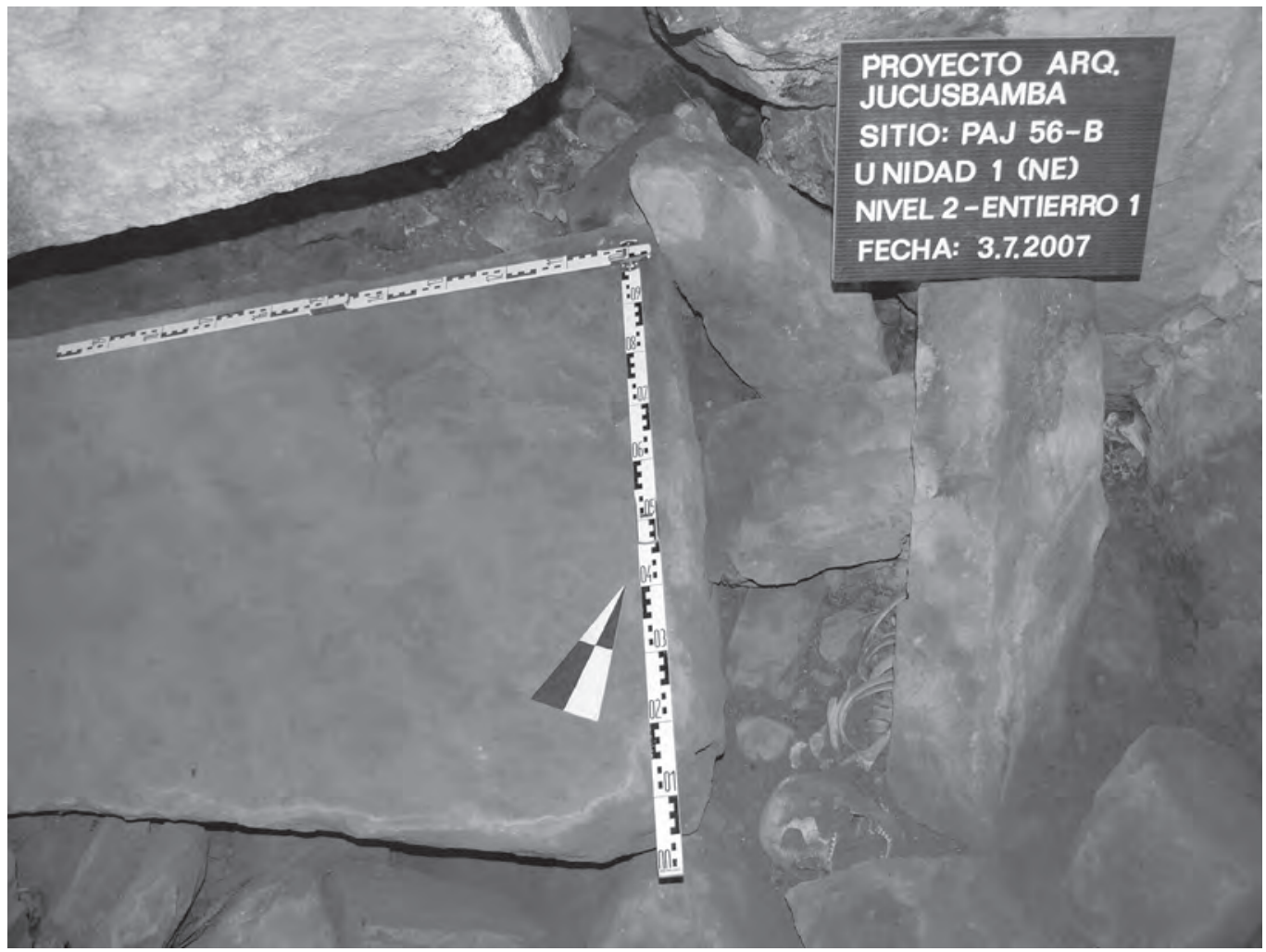

Figura 3. PAJ 56-B - Ubicación del Entierro 1 (Foto: K. Koschmieder) 


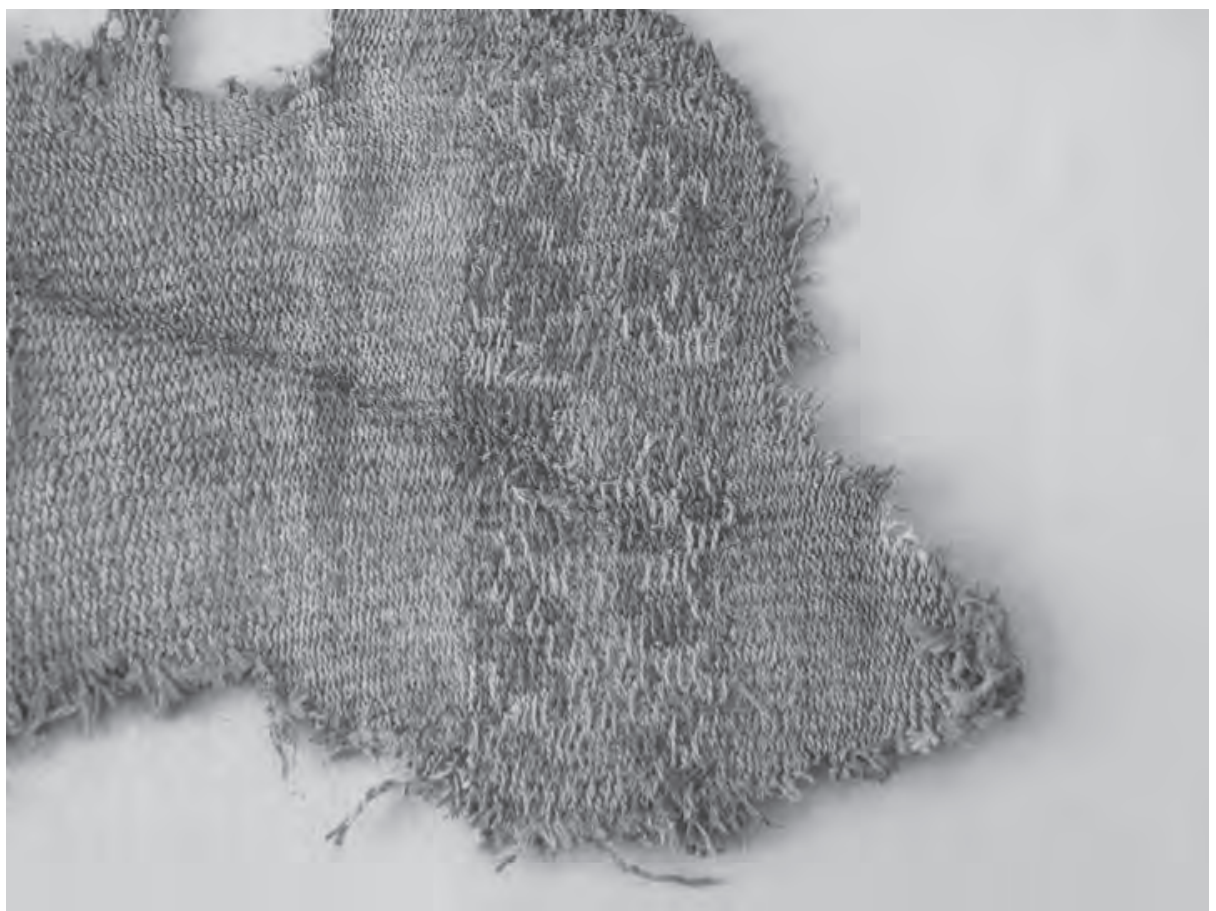

Figura 4. Entierro 1 - Paño con decoración listada y franja con motivos geométricos (Foto: A. Fernández)

huesos apareció un hacha de cobre con hoja triangular (Fig. 6), depositada encima del femur derecho del individuo. Fue manufacturada con la técnica del vaciado y pesa 322 gramos. En el extremo opuesto presenta un orificio pequeño y una muesca a cada lado del mango, posiblemente para pasar una soga o cuerda para amarrarla en algún soporte. Tiene un largo de $14 \mathrm{~cm}$, un ancho máximo de $11,6 \mathrm{~cm}$ y un espesor máximo de 0,9 cm. Debajo del esqueleto aparecieron las otras ofrendas, en primer lugar un tupu de cobre (Fig. 6) de grandes dimensiones adherido a un fragmento de textil y con un peso de 80 gramos. Tiene un largo de $32,5 \mathrm{~cm}$, un ancho máximo de $11,8 \mathrm{~cm}$ y un espesor máximo de 0,6 $\mathrm{mm}$. Fue manufacturado con las técnicas del vaciado, martillado y recortado. La "cabeza" (parte superior) es de forma elíptica y el "pie" (mango) esta ligeramente curvado. Otro objeto de metal, encontrado en el mismo contexto funerario, es un adorno (Fig. 6) en forma de cuchillo (tumi), elaborado de plata con las técnicas del laminado y recortado. Los bordes de la "hoja" están termi-

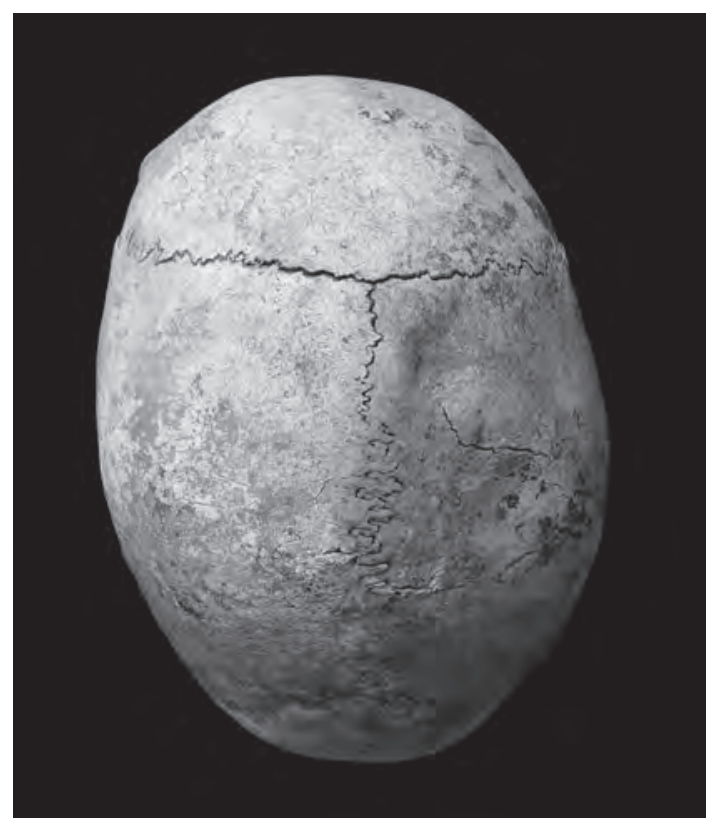

Figura 5. PAJ 56-B - Entierro 1 - Cráneo con huella de impronta de porra estrellada (Foto: C. Gaither). 


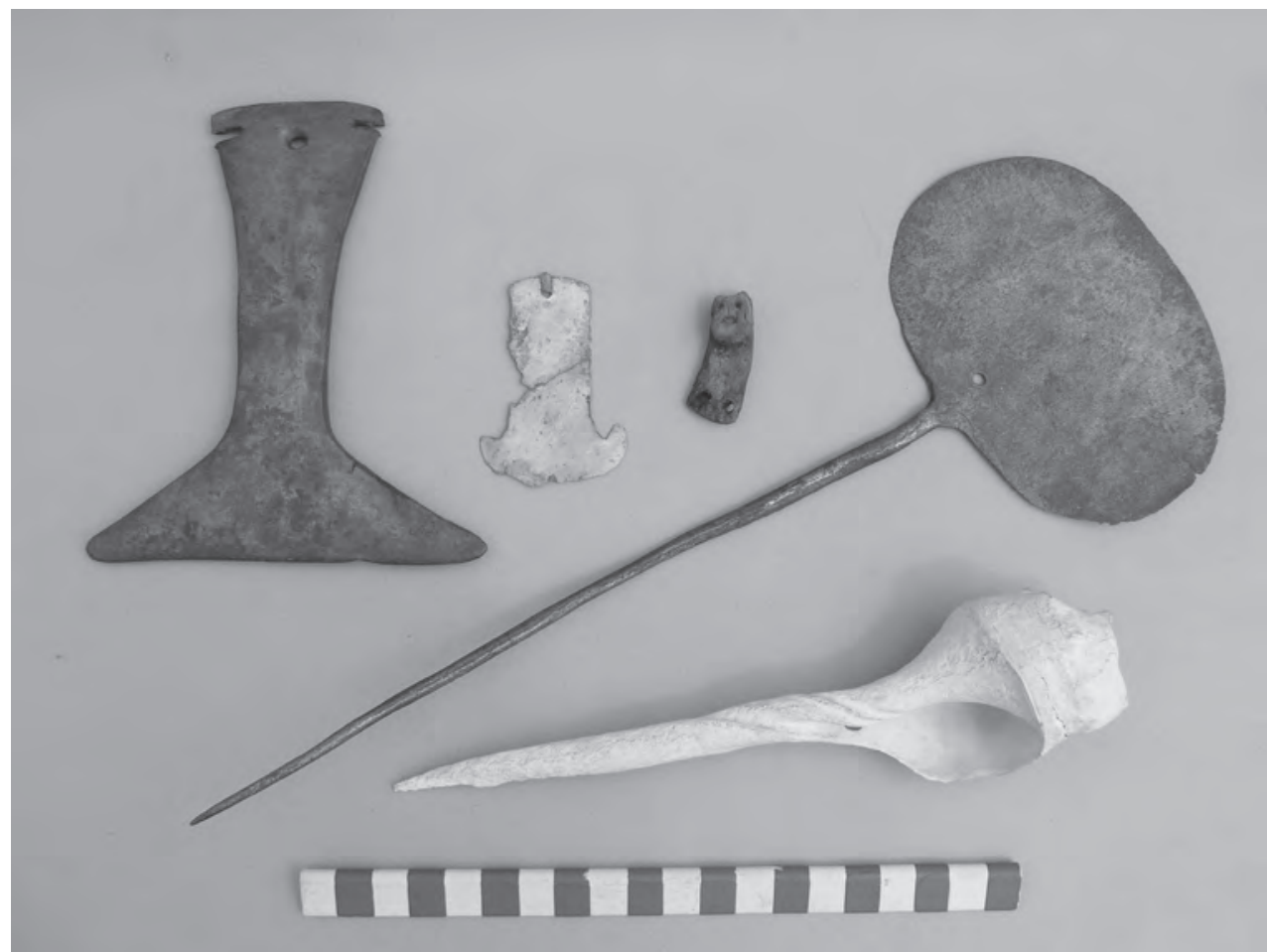

Figura 6. PAJ 56-B - Entierro 1 - Ajuar funerario (Foto: K. Koschmieder)

nando bastante cerrados, pegados al cuerpo. El objeto tiene un largo de $6,1 \mathrm{~cm}$, un ancho máximo de $4,3 \mathrm{~cm}$ y un espesor de solamente 0,5 $\mathrm{mm}$. Está dañado y presenta un "amarre" (hilo de algodón) en el extremo opuesto de la hoja. Otro objeto depositado debajo del individuo fue una flauta globular de color crema, elaborada de un caracol marino de la Familia Fasciolaridae, especie Fusinus irregularis (Fig. 6 y 7). Pesa 75 gramos, tiene un largo de $20,0 \mathrm{~cm}$ y un ancho máximo de $5,0 \mathrm{~cm}$. La posición de la entrada de aire o embocadura (Díamétro: 22-47 mm) es la parte central de la columella frente a la estoma o abertura, la cual muestra tres perforaciones circulares. Además tiene dos orificios de digitación, uno en el ápice y otro entre el ápice y el labio. $\mathrm{Al}$ soplar la parte seccionada, el aire entra por los orificios de la columella atravesando éstos y desfogando por los dos orificios de digitación, produciendo un total de 4 tonos diferentes. ${ }^{14}$ Todas las perforaciones circulares muestran un

14 Milano Trejo Huayta, com. personal. díametro que oscila entre los 3,5 a 5,0 mm. Un último agujero, ubicado en el extremo inferior o sifón de la valva, sirvió para atravesar un cordón (de transporte), de tal manera que la flauta pueda suspenderse sobre el pecho del músico. Otros objetos asociados al entierro fueron dos cuencos fragmentados con base anular del estilo Chipuric o Kuelap Pintado Alisado ${ }^{15}$ (Fig. 8), típicos para la zona de Luya. Están decorados con motivos geométricos de color rojo oscuro sobre un engobe de fondo claro. Destaca también la presencia de un objeto de madera que muestra dos orificios cerca de su base y una cara tallada, talvez imitando a un sarcófago (Fig. 6). Tiene un largo de $40 \mathrm{~mm}$, un ancho máximo de $16 \mathrm{~mm}$ y un grosor máximo de $13 \mathrm{~mm}$ a la altura de la cara, la cuál muestra cavidades que forman la boca y los ojos del ser antropomorfo.

15 El estilo Chipuric, definido por los esposos Reichlen (1950) durante sus trabajos en la provincia de Luya, es equivalente al estilo Kuelap Pintado Alisado de Ruiz Estrada (1972). 


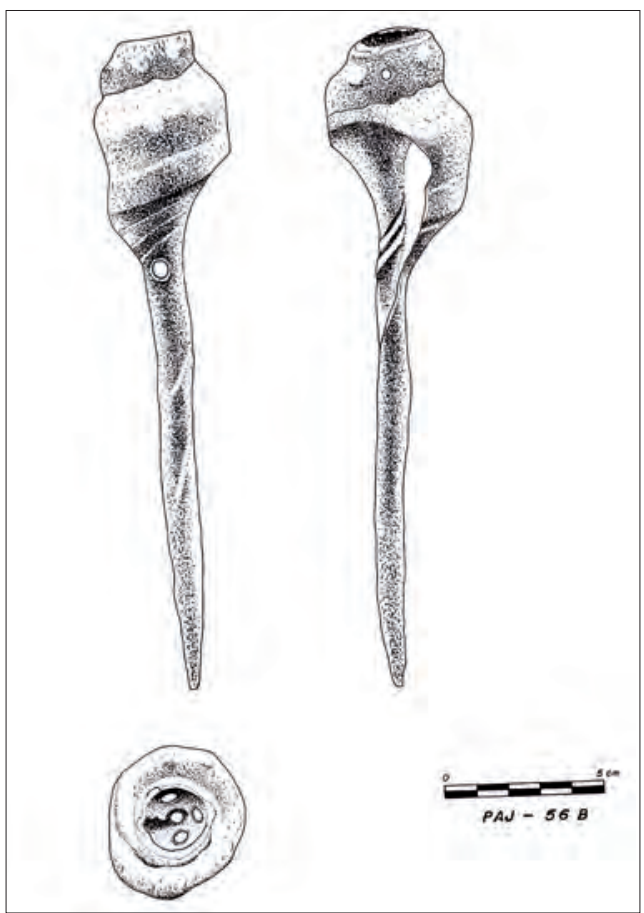

Figura 7. PAJ 56-B - Flauta globular (Dibujo: F. Farro)

\section{Entierro No. 3}

\section{El contexto arqueológico}

El entierro No. 3 se encontró "sentado" y en cuclillas (posición fetal) debajo de una roca grande y plana (Fig. 2), así que fue imposible dibujarlo. En el relleno en su alrededor se encontraron otros huesos humanos, material lítico, restos vegetales y poca cerámica diagnóstica.

\section{Análisis Osteológico}

Los análisis del cráneo y del fémur derecho revelaron que se trataba de un hombre adulto con una estatura de $158,4 \pm 3,4 \mathrm{~cm}$ y una edad de 35-45 años al momento de su muerte. ${ }^{16}$ Las patologías incluyen fracturas curadas, las cuales estan presentes en los siguientes huesos craneales: El maxilar superior izquierdo (una fractura

16 La estimación del sexo se basa en la morfología craneal y la edad se calculó en base a la sutura del cráneo y el desgaste de los dientes.

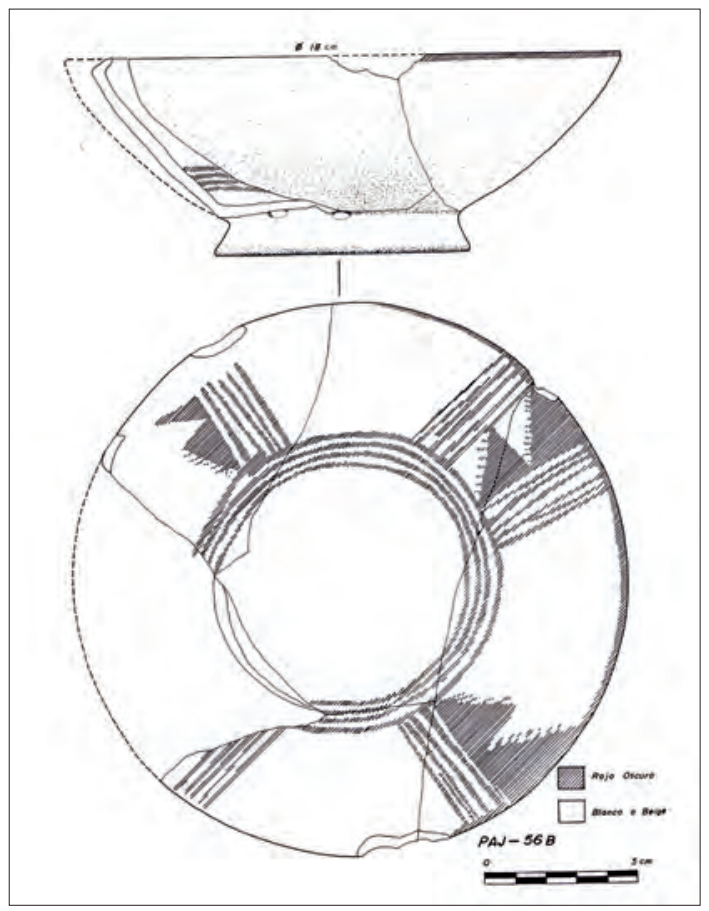

Figura 8. PAJ 56-B - Cuenco con base anular (Dibujo: F. Farro).

de 21 x 10 mm - Fig. 9), el hueso nasal izquierdo con huellas de deformación (Fig. 10), el hueso parietal izquierdo y otra herida cerca del breg$\mathrm{ma}^{17}$ (una fractura ovalada de $20 \times 17 \mathrm{~mm}$ - Fig. 11). Todas estas fracturas sanaron por completo. También está presente una trepanación en el hueso parietal izquierdo. ${ }^{18}$ Se puede observar un orificio circular que mide $22 \times 21 \mathrm{~mm}$ (Fig. 12). Parece que el tamaño original del defecto fue de 50 × $38 \mathrm{~mm}$, pero la actividad osteoblástica reconstituyó la parte afectada (por la intervención quirúrgica) hasta que quedó un agujero de tan sólo 22 x $21 \mathrm{~mm}$. Los bordes del orificio están bien definidos. La trepanación fue realiza-

17 El bregma es un punto en el cráneo que se encuentra en la parte superior cerca de la frente.

18 En varios sitios Chachapoya fueron registrados cráneos con fracturas y trepanaciones con una tasa de hasta $20 \%$ para las muestras (p.e. Bracamonte 2002, 2004; Fabre 2008; Fabre et al. 2008; Jacobsen et al. 1986-1987; Nystrom 2004; Ruiz 1994; Schjellerup 2005; Zubiate 1984). 


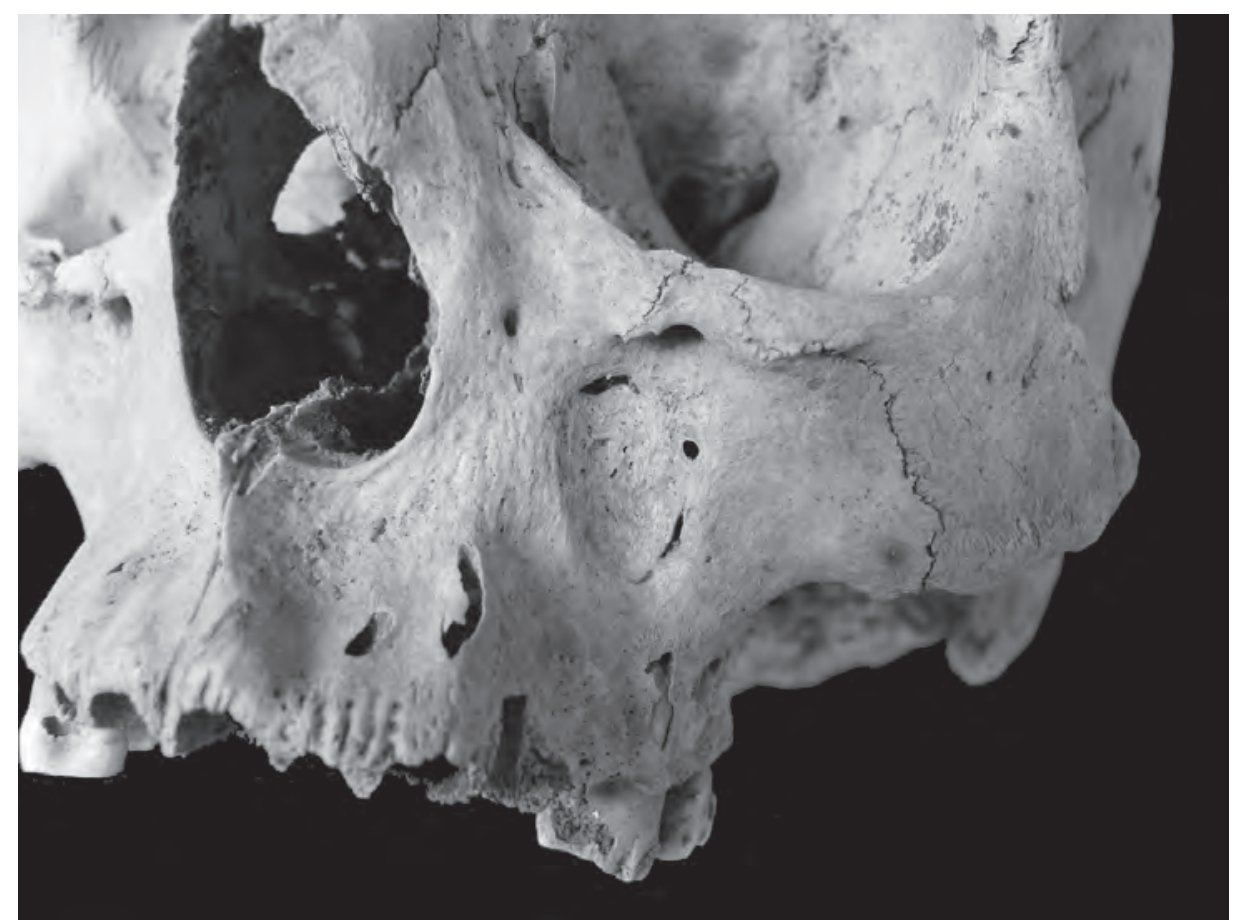

Figura 9. PAJ 56-B - Entierro 3 - Fractura curada en el maxilar (Foto: C. Gaither)

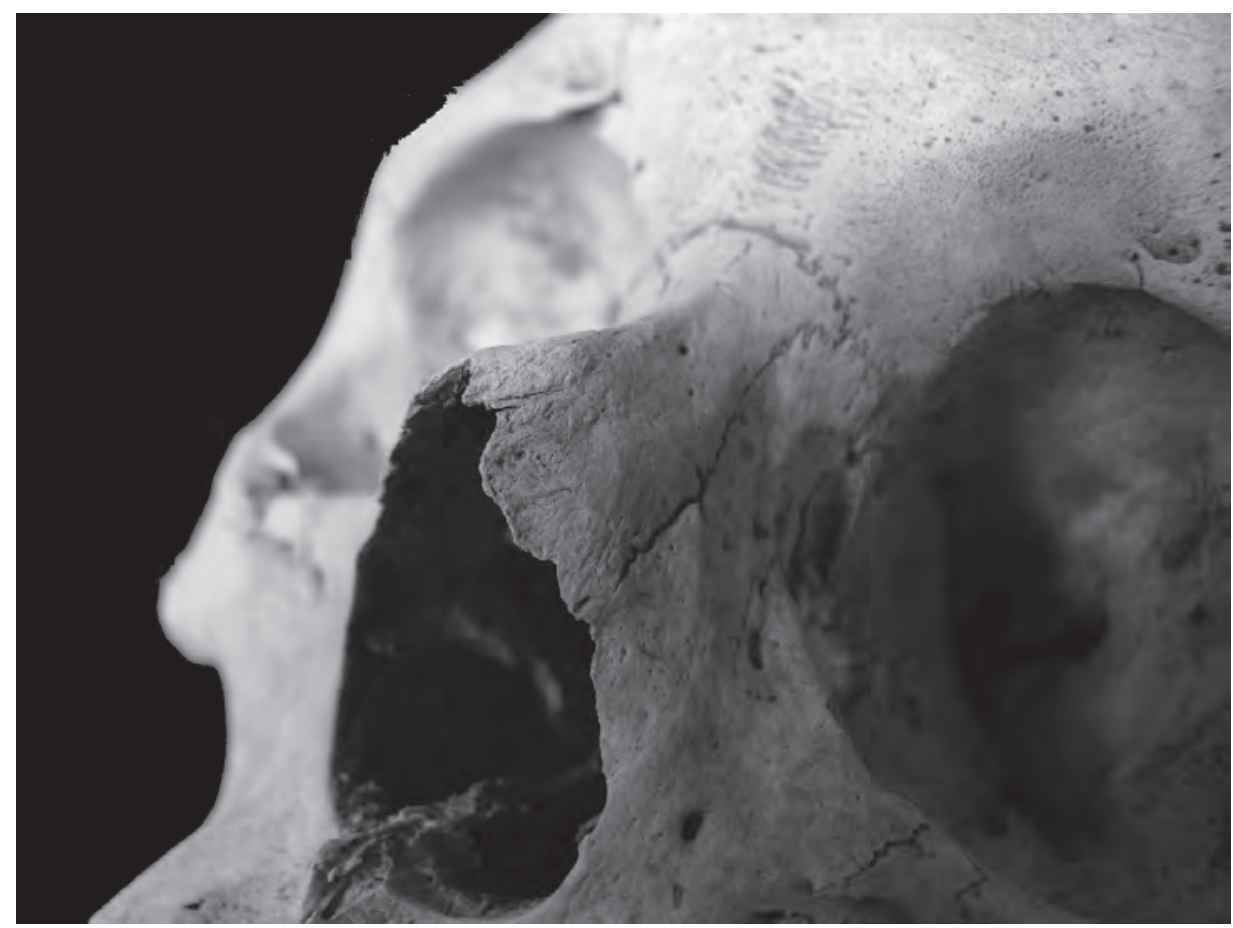

Figura 10. PAJ 56-B - Entierro 3 - Fractura curada en la nariz (Foto: C. Gaither). 


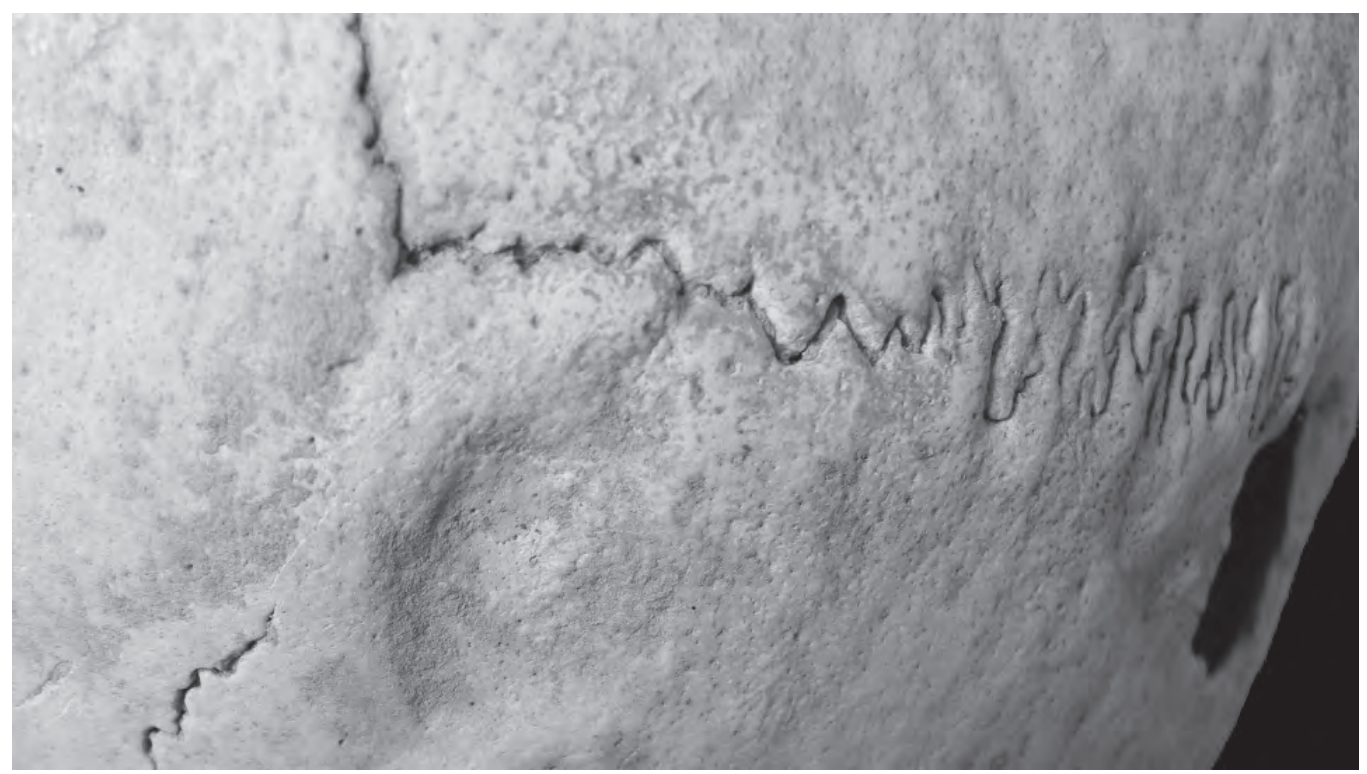

Figura 11. PAJ 56-B - Entierro 3 - Fractura curada en el hueso parietal (Foto: C. Gaither).

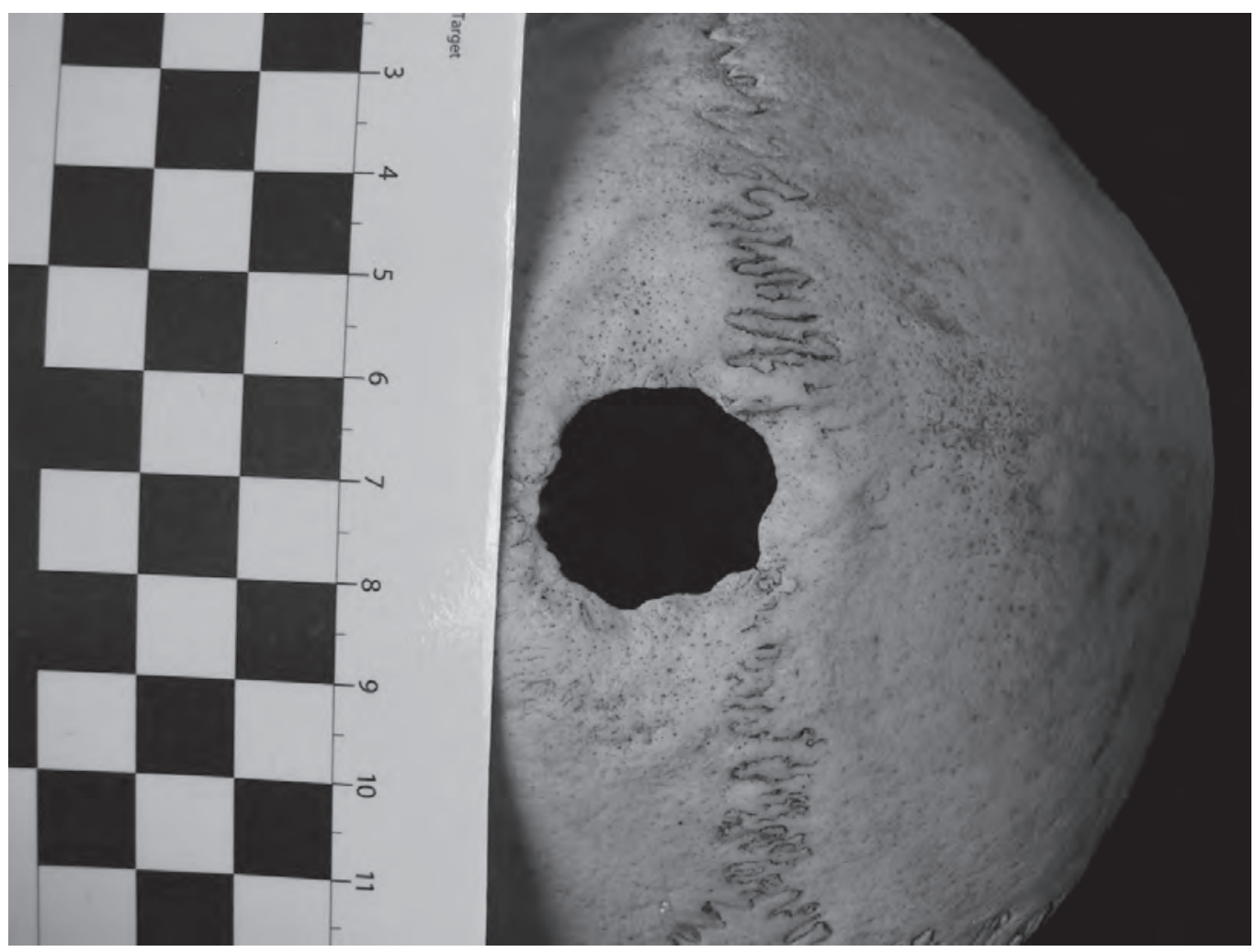

Figura 12. PAJ 56-B - Entierro 3 - Trepanación (Foto: C. Gaither). 
da con la técnica del raspado, posiblemente con un objeto de obsidiana. La zona de intervención quirúrgica se curó completamente, lo que demuestra la remodelación ósea y la ausencia de periostitis. Otras anomalías, registradas en el cráneo, incluyen una hiperostosis porótica en el hueso occipital, un gran agujero en la pars lateralis (parte de la base del cráneo), metopismo ligero, un doble agujero supraorbitario derecho, suturas completas infraorbitarias y múltiples agujeros pequeños cigomáticos faciales.

Las patologías dentales incluyen la presencia de caries y un absceso periapical de la raíz distal bucal. Todos los dientes muestran un desgaste moderado a severo.

\section{Resumen}

Los dos esqueletos de hombres adultos, identificados en PAJ 56-B, muestran lesiones múltiples en el cráneo. Uno de los individuos (Entierro No. 3) tiene fracturas en el hueso parietal, en los huesos nasales y en el maxilar superior. Todas estas fracturas se ubican en el lado izquierdo, las que atribuimos a una pelea, cara a cara, con un atacante diestro. En el cráneo se observa también un orificio de trepanación curado. Se puede asociarlo a las fracturas múltiples que tenía el hombre a causa de los golpes que recibió. El curandero hizo la cirugía para calmar los dolores y curar al paciente (y tuvo éxito). El otro individuo (No. 1) también muestra fracturas multiples en el cráneo. Una de las heridas fue provocada por un arma contundente que fue muy común para esta época (porra estrellada). Este individuo tuvo también una fractura en uno de los huesos de la mano - el metacarpiano. Las heridas que identificamos en ambos entierros son típicas para las que reciben los guerreros durante unos enfrentamientos bélicos.

\subsubsection{PAJ 113 (Lengache)}

El abrigo rocoso PAJ 113 (Lengache), que se ubica a unos 4 a $5 \mathrm{~km}$ hacia el noreste del pueblo de Lámud (Fig. 1), fue registrado durante los trabajos de prospección el 11 y 12 de julio del 2007. Se encuentra a una altura de 2468 msnm entre las siguientes coordenadas UTM: E 0177584 y N 9324884. La quebrada de Lengache tiene la mayor concentración de restos arqueológicos en la zona de investigación. Destacan muros de contención, estructuras circulares, pinturas rupestres, chullpas, pequeñas cuevas con entierros y varios grupos de sarcófagos (PAJ 111), algunos encima de plataformas con enlucido pintado.

El abrigo rocoso cubre un área de aproximadamente 7,4 x 3,6 m (la altura es de 1,0-2,4 $\mathrm{m})$, delimitado por un muro de contención de poca altura en la parte sureste del sitio (Fig. 13). Este muro sirvió para nivelar el interior del abrigo y para colocar un apisonado, sobre el cual hay evidencias de quemas. Los entierros se concentran entre varias rocas caídas y la roca madre, los más importantes en la parte noreste del lugar.

En las paredes de las rocas se pudo observar una gran cantidad de pinturas rupestres de color rojo oscuro, las cuales muestran seres humanos, animales (camélidos/venados) y motivos abstractos. Destacan las representaciones de varios guerreros con tocados ${ }^{19}$, los cuales llevan un bastón con cuchillo (tumi) y en un caso también una porra (estilizada) (Fig. 14). Estos dos objetos siempre están representados en escenas de combate con otros grupos (Fig. 15) y en los encuentros con animales silvestres. La pintura más interesante de nuestro sitio de investigación (PAJ 113) se ubica encima de un relleno de piedras amontonadas. Muestra un personaje que sujeta en una mano un cuchillo y en la otra una cabeza cortada (Fig. 16).

Entre el 19 y 22 de setiembre del 2007 realizamos excavaciones arqueológicas en la parte nororiental del abrigo (Fig. 17), donde se ubicó una sospechosa concentración de piedras entre dos rocas caidas y la roca madre (con un ancho de solamente $60 \mathrm{~cm}$ ). Como en el caso de PAJ 56-B el estado de conservación del sitio fue muy bueno.

19 A veces los guerreros fueron representados con una cabeza en forma de cuchillo (tumi) como se puede apreciar en una escena del sitio PAJ 219 (Ajingo - Fig. 18). 


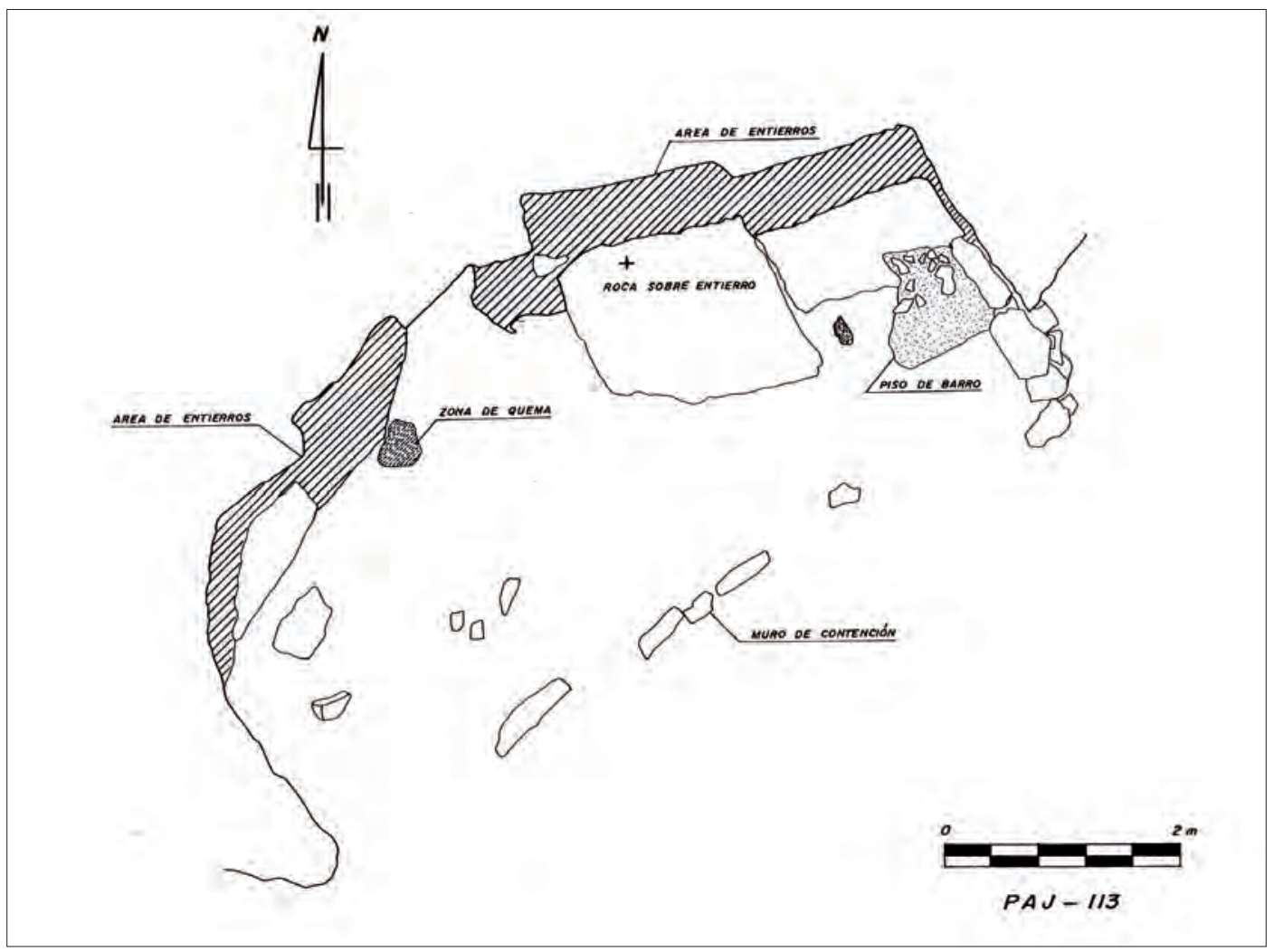

Figura 13. Mapa - PAJ 113 (Dibujo: K. Koschmieder).

Entierros No. 1 y 2

\section{El contexto arqueológico y análisis osteológico}

Al retirar las piedras amontonadas entre la roca más grande (caida) y la roca madre aparecieron dos esqueletos de bebés, los cuales murieron a una edad de solamente 9 a 12 meses. ${ }^{20}$ Hay fuertes indicios de desnutrición ${ }^{21}$, la cuál fue la causa para varias enfermedades crónicas como periostitis, mastoiditis (infección de los oidos), meningitis y osteoporosis. La osteoporosis, detectada en los huesos largos del primer niño, fue probablemente la consecuencia de un proceso de mala nutrición. La periostitis de la diáfisis de la tibia del mismo individuo es un indica-

20 La estimación de la edad se basa en el desarrollo dental y en el tamaño de los huesos largos. El sexo es indeterminado, debido a la corta edad de los niños.

21 La gran cantidad de esqueletos de niños registrados en el sitio de Los Pinchudos refleja una vez más que las condiciones de salud no eran buenas para los infantes (Bracamonte 2004: 19). dor de estrés y se debe a los problemas crónicos de su mala salud. A parte de los síntomas carenciales se detectó una fractura perimortem en el cráneo, la cuál probablemente causó la muerte del niño. El hueso parietal izquierdo muestra roturas concéntricas irradiadas en la bóveda craneal externa, un rasgo típico después de recibir un golpe con un arma contundente. En el esqueleto del otro subadulto detectamos periostitis en la parte interior del cráneo, la cuál podria haber sido el resultado de un trauma en el cráneo. Los dos individuos fueron depositados en el relleno que cubre los entierros principales, lo que deja de suponer que fueron sacrificados al mismo momento.

\section{Entierros No. 3 y 4}

El contexto arqueológico y análisis osteológico

Al retirar todo el relleno aparecieron los otros dos individuos principales debajo de la roca 


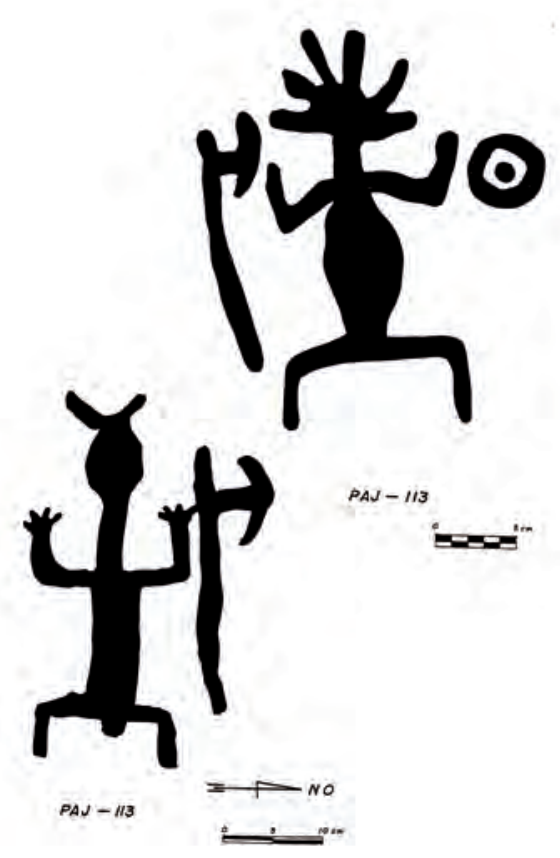

Figura 14. PAJ 113 (Lengache) - Pinturas rupestres - Guerreros (Dibujo: K. Koschmieder).

más grande. Se trata de un hombre de aproximadamente 50 años y un niño de 6 a 8 años al momento de sus muertes. Los dos estaban enterrados en cuclillas, uno al lado del otro, pero no sabemos en que posición fueron colocados, ya que la mayoría de sus huesos han sido removidos por roedores.

\section{Entierro No. 3}

Del adulto recuperamos solamente el cráneo y la mandíbula. Las patologías señalan una hiperostosis porótica en el hueso parietal derecho y cerca de la sutura escamosa en el occipital. Es un indicio de que este individuo sufría de anémia en algún momento de su vida. Una fractura perimorten está presente en la base del cráneo al lado izquierdo del agujero occipital. El hueso está aplastado en ambas partes de la bóveda craneal y muestra una pequeña fractura en forma radial que se prolonga hacia la parte media del occipital. También hay evidencias de un corte que ha ocasionado la pérdida del cóndilo occipital izquierdo.

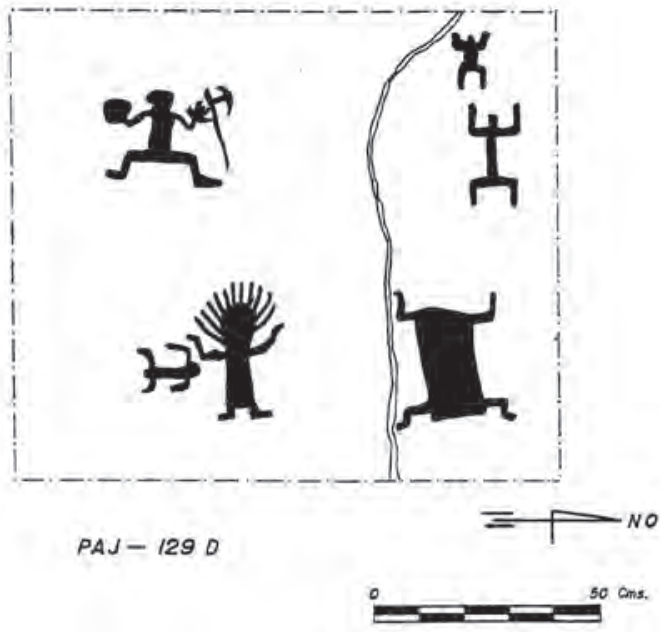

Figura 15. PAJ 129-D

Pinturas rupestres - Caza de cabezas trofeo (Dibujo: K. Koschmieder)

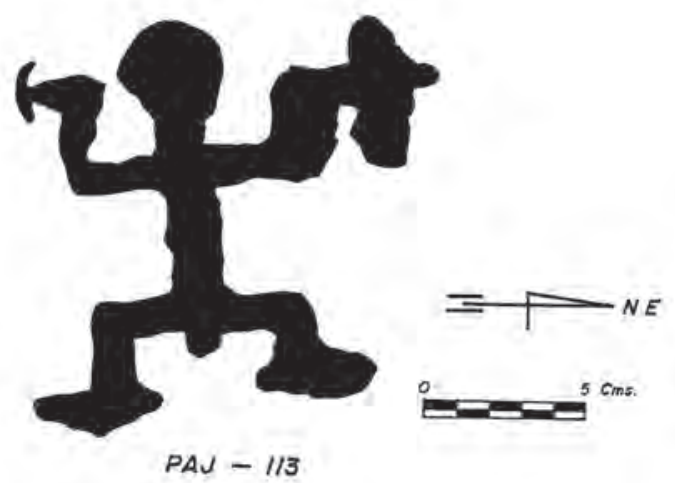

Figura 16. PAJ 113 (Lengache) Pintura rupestre - "Degollador" (Dibujo: K. Koschmieder)

Entierro No. 4

El niño alcanzó una edad de sólo 6 a 8 años, así que no era posible determinar su sexo. Las patologías detectadas incluyen anémia y periostitis, la última un indicio que el niño estaba en mal estado de salud al momento de su muerte. Murió a causa de un fuerte impacto con un arma contundente, ya que el cráneo fue destrozado en su lado izquierdo (Fig. 19). El punto de impacto parece haber sido el hueso parietal izquierdo, lo que demuestran las fracturas concéntricas en este lugar. 


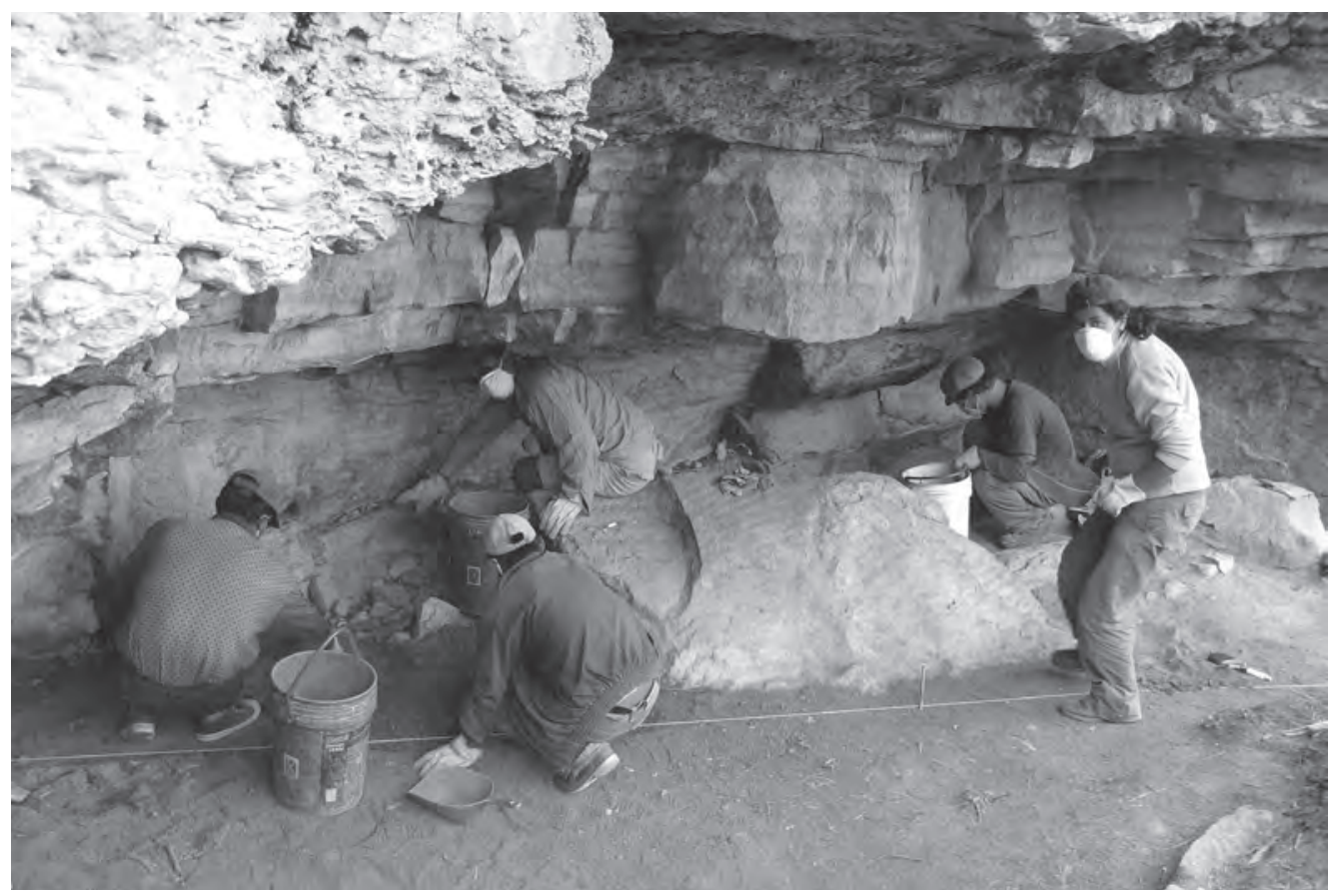

Figura 17. PAJ 113 (Lengache). Abrigo rocoso. (Foto: K. Koschmieder)

Una fractura radial atraviesa la sutura coronal y continúa en el hueso frontal, lo que indica un golpe fuerte y letal. El trauma está también presente en el hueso occipital, en el agujero magno, en la clavícula izquierda y en la escápula izquierda.

\section{Las ofrendas}

A un lado del cráneo del niño se encontró un ceramio con base anular y borde expandido, lo que sugiere una influencia Inca (Fig. 20). Tiene una altura de $16 \mathrm{~cm}$ y un ancho máximo de $11 \mathrm{~cm}$ a la altura del cuerpo. La vasija lleva en el hombro dos pequeñas asas verticales, mientras en el cuerpo y encima del borde se observan lineas paralelas en forma horizontal y vertical, pintadas con un color rojo ocre. Otros fragmentos de cerámica, hallados en el lugar, son de la tradición Chachapoya, como bordes arqueados (Ruiz 1972) o tiestos con pinturas y aplicaciones.

Asociados a los dos entierros se encontraron también material lítico, restos vegetales (maíz, lúcuma) y óseo animal de llama y venado. Destaca el hallazgo de un casco de caballo, encontrado cerca del cráneo del adulto (Fig. 21), un valioso testimonio para poder fechar los contextos funerarios. Podemos postular que los incidentes violentos sucedieron durante el período Colonial Temprano. Es de suponer que el casco de caballo tenía un gran valor para la gente autóctona, ya que este animal extraño y temido por ellos, no lo conocían antes de la llegada de los españoles.

\section{Resumen}

Los individuos, enterrados en el abrigo rocoso, muestran evidencias de fracturas (trauma), especialmente en sus cráneos. Hemos detectado a lo menos dos momentos de violencia. Los dos personajes principales, el adulto y el joven de 6 a 8 años, murieron durante un enfrentamiento, mientras para la muerte de los dos pequeños, los cuales se encontraron en el relleno, no tenemos una explicación satisfactoria. Podría ser que fueron en el mismo acto de violencia o sacrificados para acompañar al personaje principal (el adulto), probablemente un guerrero, ya que a la altura de la tumba encontramos la pintura rupestre de un hombre con cuchillo y cabeza trofeo. 


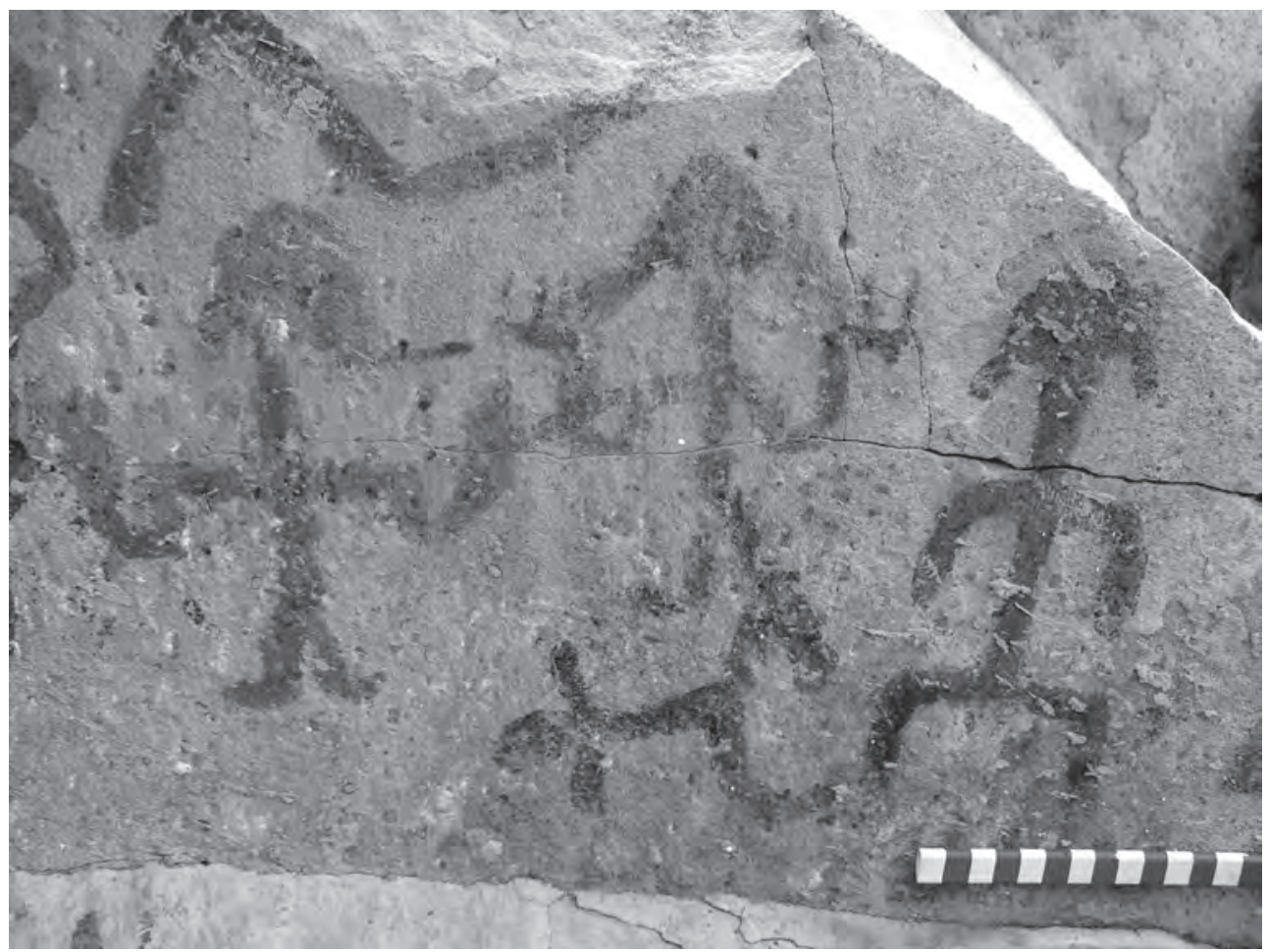

Figura 18. PAJ 219 (Ajingo). Pinturas rupestres de guerreros (Foto: K. Koschmieder)

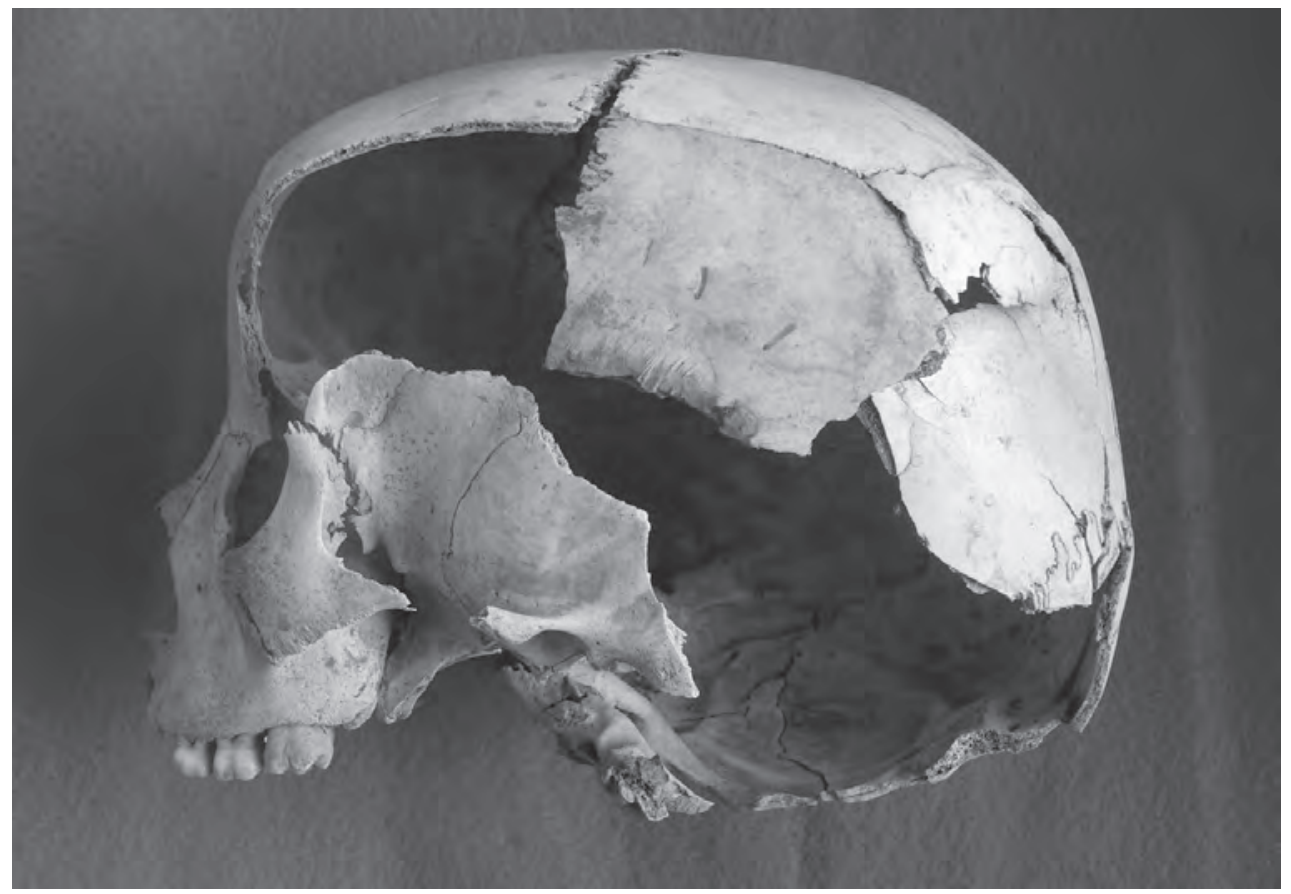

Figura 19. PAJ 113 (Lengache) - Entierro 4 - Cráneo destrozado (Foto: C. Gaither) 


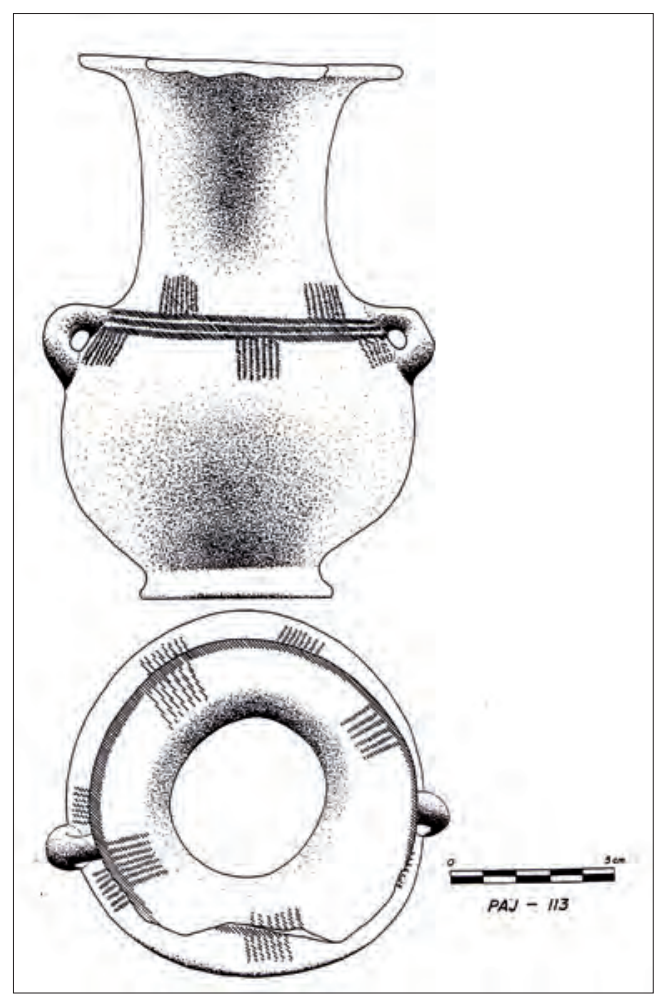

Figura 20. PAJ 113 (Lengache) - Vasija Chachapoya-Inca (Dibujo: F. Farro)

\section{Discusión}

\section{(INTERPRETACIÓN DE LOS RESULTADOS)}

Las formas de enterramiento de los Chachapoya fueron las más diversas en todo el área andina, las que atribuimos a la existencia de varios subgrupos con diferentes tradiciones funerarias

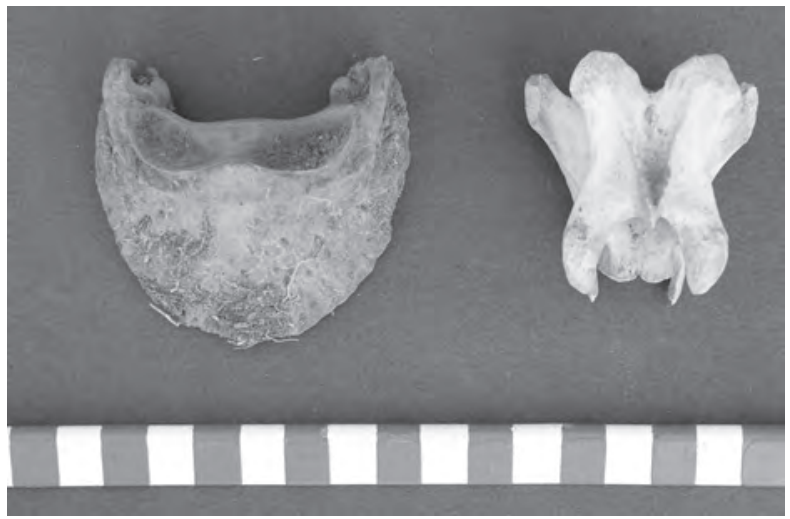

Figura 21. PAJ 113 (Lengache). Casco de caballo y vertebra de venado (Foto: K. Koschmieder) y a la presencia de varios grupos sociales en las sociedades Chachapoya. Mientras personas de las clases bajas fueron enterrados en un sinnúmero de lugares, como en sus viviendas circulares o en cuevas, sus jefes (curacas) y guerreros encontraron su última morada en estructuras más elaboradas, como chullpas decoradas o sarcófagos de gran tamaño. Pero existen otros lugares con evidencias de tumbas que pertenecen a individuos de alto rango, como p.e. los abrigos rocosos.

Las evidencias encontradas en la provincia de Luya, dejan de suponer que los abrigos rocosos sirvieron como lugares de enterramiento para los guerreros Chachapoya o por lo menos para personas vinculadas a actividades belicosas. Todos los esqueletos de adultos, identificados en los sitios PAJ 56-B y PAJ 113, muestran fracturas en el cráneo, productos de golpes recibidos durante algún enfrentamiento con otras personas.

En un caso se observa también una trepanación, la cuál fue realizada para curar al personaje gravemente herido. En el mismo sitio (PAJ 56-B) otro individuo muestra la huella de impronta de una porra estrellada en el hueso parietal derecho del cráneo. Este mismo personaje fue enterrado con objetos de metal, cuencos de cerámica, una flauta globular elaborada de un caracol marino, un objeto de madera en forma antropomorfa, cuentas de collar y algunos alimentos (cuy y maíz). Estuvo envuelto en textiles decorados, fabricados con hilos de fibra

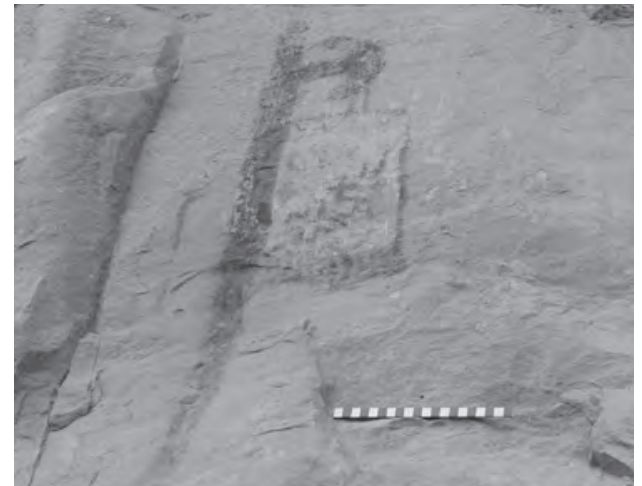

Figura 22. PAJ 70-E (Pueblo de los Muertos) - Pintura rupestre - Bastón con cuchillo $y$ "emblema" (Foto: K. Koschmieder) 


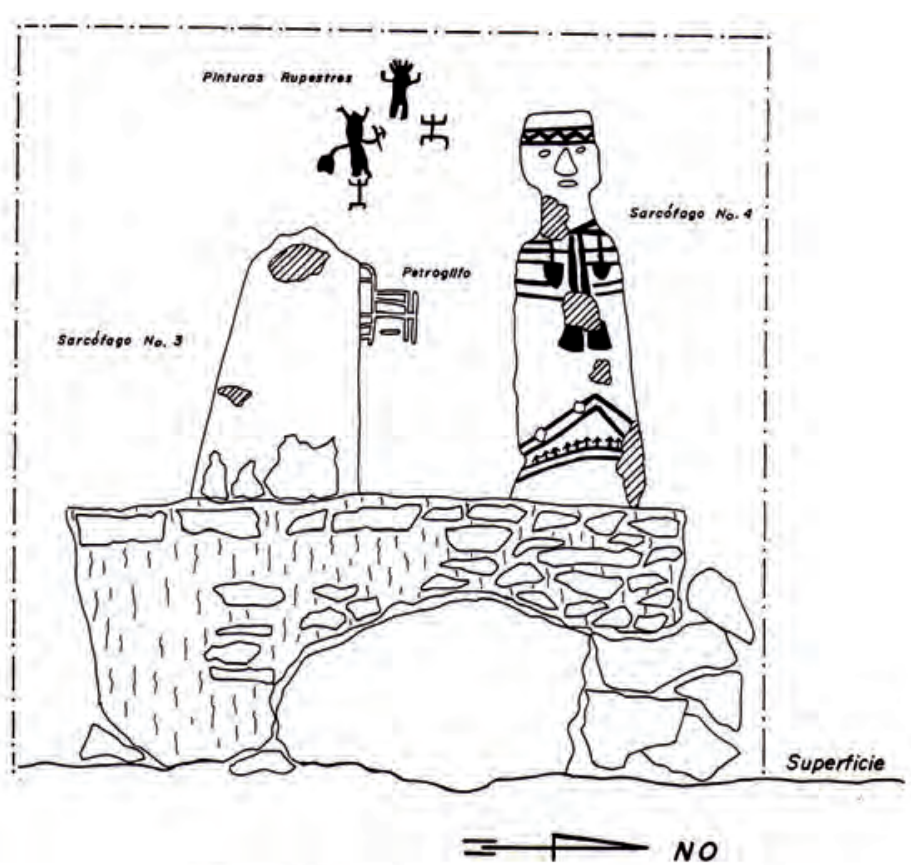

$P A J-145 B$
0

Figura 23. PAJ 145-B (Pullia) - Sarcófagos, petroglifos y pinturas rupestres con escena de caza de cabezas trofeo (Dibujo: K. Koschmieder)

de camélidos (lana). Asociado a uno de los textiles encontramos un tupu de cobre de gran tamaño. Normalmente los tupus grandes están asociados a las mujeres, como demuestran las pinturas murales de Kacta (PAJ 237) u otras representaciones en los sarcófagos de la zona. En todos los casos los tupus cuelgan en el pecho de las mujeres. Extraño es también la flauta globular en el ajuar funerario. Podria pertenecer a un hombre que tenía la función de tocar el instrumento durante una batalla para animar con el sonido a los guerreros (véase Silva 2006). Los entierros de PAJ 56-B pertenecen al período Pre-Inca (Intermedio via. Los guerreros, represen tados en las rocas, llevan un bastón con cuchillo (tumi), su símbolo de identidad. A veces este bastón tiene sujetado una especie de emblema o estandarte, como en los sitios de Tingorbamba (PAJ 70-E Fig. 22) y Choclic (Ruiz 2009 b). Posiblemente constituía un medio para reconocer la identidad del grupo. El bastón con cuchillo aparece especialmente en escenas de caza de cabezas trofeo, como p.e. en los sitios PAJ 129-D (Fig. 15) o PAJ 145-B (Fig. 23). ${ }^{22}$ Las armas utilizadas por los guerreros fueron las hondas, las porras redondas y estrelladas, y las lanzas. Según Garcilaso (1965 [1609], lib. VIII, cap. I: 291) "la honda...es la principal arma que en la guerra usaban...". Proyectiles para hondas encontramos en las viviendas circulares y en los contextos funerarios (Koschmieder 2008: 25; Koschmieder/Paredes 2007: 13), pero abundan en sitios fortificados como en la ciudad fortificada de Kuelap (Narváez 1988: 122, 1996 a: 101). Las porras utilizaban para la lucha cuerpo a cuerpo. La mayoría de las fracturas están asociadas a las armas contundentes. Una porra estrellada se halló en un contexto funerario de Chichita (PAJ 250). Una mujer, enterrada debajo del piso de su vivienda, carecía de su cráneo. En su lugar fue depositada la porra, talvez un indicio en que forma murió (Zetzsche/Koschmieder 2010: 40). Según Schjellerup (2005:
22 La caza de cabezas trofeo está también presente en los petroglifos de Putquerurco (PAJ 235-A), donde entre otros un personaje pisa dos cabezas seccionadas (Fig. 24). 
126) las lanzas (de chonta) eran las armas más importantes que poseían los Chachapoya y se las adjudicaba un poder especial. ${ }^{23}$

La caza de cabezas trofeo fue común entre los subgrupos Chachapoya y fue practicada hasta tiempos coloniales:

“...los naturales muy belicosos, amigos de la guerra y de cortar cabeças..." (Salinas Loyola 1965 [1571], III: 197)

Colocaron las cabezas trofeo de los Incas vencidos en sitios visibles:

"...los chachapoya tomaron las cabezas de Chuquis Huaman y demás indios principales que habian muerto, y las pusieron en las puertas de sus casas por trofeo e insignia de su valentia..." (Murúa 2001 [1611]: 150)

En el arte rupestre de la provincia de Luya registramos una gran cantidad de escenas de caza de cabezas de trofeo (pinturas rupestres y petroglifos - ver también Aguilar 1997). ${ }^{24}$ Una de las representaciones decora la roca en el abrigo rocoso de Lengache (PAJ 113 - Fig. 16), exactamente encima de la tumba del presunto guerrero. Este muestra fracturas en el cráneo, al igual que los tres niños que lo acompañaban ${ }^{25}$. El hallazgo de una vasija Chachapoya-Inca y de un casco de caballo (colonial), al igual que las declaraciones de los cronistas, demuestran que la caza de cabezas trofeo continuó hasta los tiempos coloniales.

Representaciones de cabezas trofeo son comunes en algunas culturas prehispánicas (p.e. Moche), pero en el caso de los Chachapoya podrian reflejar su proximidad a los grupos amazónicos como los jivaro, reconocidos "reducidores

23 Para la provincia de Luya no hay evidencias arqueológicas para el uso de este tipo de arma.

$24 \mathrm{En}$ el arte rupestre fuera de la provincia de Luya casí no existen escenas de la caza de cabezas trofeo. Una excepción es La Petaca, donde una pintura de grandes dimensiones muestra la decapitación de una victima (Muscutt 1998: 47, 53).

25 No sabemos si los niños fueron muertos por los atacantes o si fueron sacrificados para acompañar al supuesto guerrero (sus hijos?).

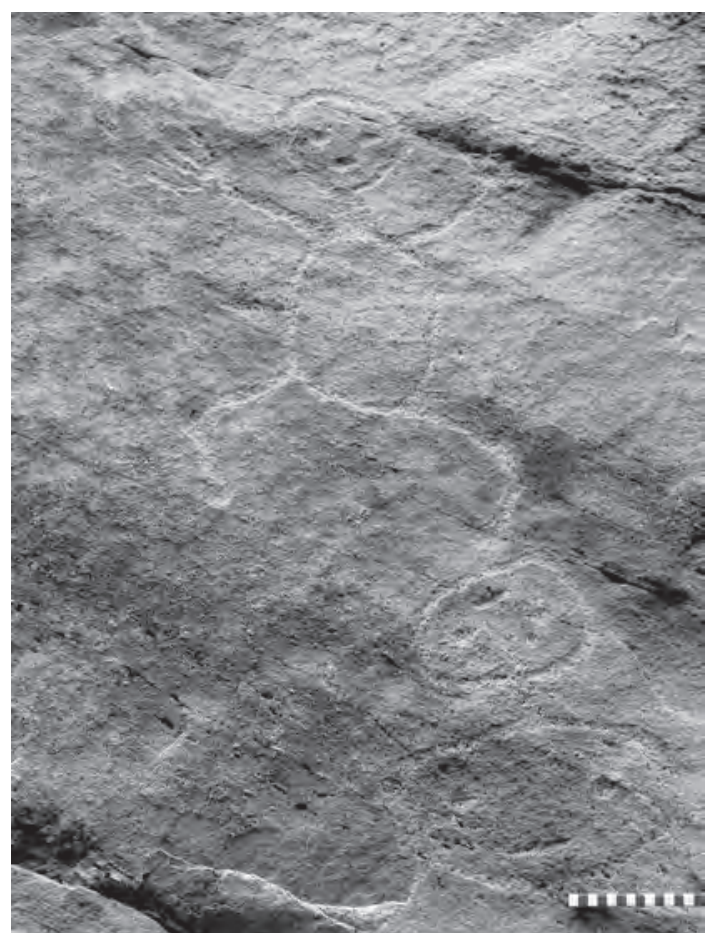

Figura 24. PAJ 235-A (Putquerurco) Petroglifos (Foto: K. Koschmieder)

de cabezas" hasta tiempos históricos (Karsten 1935).

Es muy probable que algunos guerreros también fueron enterrados en sarcófagos especiales. Como mencionamos anteriormente, la forma de enterrar los muertos en sarcófagos de piedra y barro fue muy común para un subgrupo Chachapoya que ocupaba la zona norte de la provincia de Luya. Registramos los restos mortales de hombres, mujeres, niños y bebés en sitios como Ayachaqui (PAJ 206). Una excepción son las grandes estatuas, elaboradas de caña y barro, que alcanzan alturas entre 1,4 y 2,5 m. En el sitio de Pullía (PAJ 145-B) se ubican dos sarcófagos encima de una plataforma. Están asociados con pinturas rupestres que muestran varios individuos, entre ellos un personaje con tocado de asta de venado que lleva el típico bastón con cuchillo y en la otra mano una cabeza cortada (Fig. 23). Suponemos que los hombres enterrados en estos sarcófagos fueron guerreros que practica- 
ban la caza de cabezas trofeo. Otros sarcófagos, algunos encima de plataformas con enlucido pintado ${ }^{26}$, muestran una cara de miniatura modelada encima de la cara-máscara, simbolizando una cabeza trofeo (Fig. 25). En el sitio de Karajía algunas cara-máscaras terminan en punta, actuando de receptáculo para un verdadero cráneo (Fig. 26). Según Kauffmann (2003: 210) se trataba originalmente de cabezas momificadas. Una delgada cuerda sujeta las mandíbulas. En el interior de uno de los sarcófagos se pudo observar un cráneo con evidencias de fracturas y una trepanación (ibid.: 211), talvez los restos mortales de un guerrero o de un curaca que murió a causa de un enfrentamiento.

Algunos cronistas españoles mencionaban figuras extrañas en los acantilados, probablemente sarcófagos antropomorfos:

"En la provincia de los Chillaos ay una peña en la qual están esculpidas y estampadas unas figuras...tenidas en mucha veneración de los indios de esta provincia, por que tienen por tradición de sus (ante)pasados de unos en otros de inmemorable tiempo..." (Vásquez de Espinoza 1948 [1626]: 376)

Según un documento de 1574 los Inca acusaban al curaca Chuquimis de Cochabamba de haber envenenado a Huayna $\mathrm{Capac}^{27}$. El capitán Inca Colla Topa, hermano de Huayna Capac, se dirigió a la tierra natal de Chuquimis para castigarlo. Sin embargo, Chuquimis ya habia muerto. Colla Topa ordenó de

“...sacar los huesos donde estaban, en unos peñascos, a donde antiguamente ponían las sepolturas por más honra, y los mandó enterrar..." (Espinoza 1967: 320)

Espinoza (ibid.: 246), quién publicó el documento, apunta que fue una "urna funeraria hecha de arcilla con figura humana...que estaba colocada en una cueva situada a unos altos peñascos", aludiéndose a un sarcófago, de lo cuál

26 Una de las plataformas pintadas en Lengache (PAJ 111-A) muestra el dibjo de un bastón con cuchillo.

27 El supuesto „incacidio“ no es mencionada en ninguna otra fuente. los Inca extrajeron los restos mortales de Chuquimis para profanarlos.

\section{¿Chachapoya o Chillaos?}

Nuestro área de investigación se ubica entre los rios Jucusbamba y Utcubamba en la provincia de Luya (Fig. 1). Los sitios funerarios (p.e. abrigos rocosos) y otros restos arqueológicos, identificados en esta zona, pertenecían a uno de los muchos subgrupos de la tradición Chachapoya. La forma de enterrar los muertos en sarcófagos, algunos detalles arquitectónicos ${ }^{28}$ y la presencia predominante de la cerámica (pintada) Chipuric o Kuelap Pintado Alisado ${ }^{29}$, son propios de la zona norte de la actual provincia de Luya.

Algunos autores (p.e. Narváez 1988, 1996 b; Ruiz 2009 a; Zevallos 1995) postulan, que un grupo llamado Chillao ocupaba en tiempos preincaicos una zona amplia que incluía también la actual provincia de Luya. Supuestamente esta macro-etnia no pertenecía a los Chachapoya:

“...los Chillaos, que era la nación más importante a la llegada de los Incas. ...existieron grandes grupos de diferentes naciones, y que los Chacha fueron de menor relevancia." (Narváez 1996 b: 98).

“...hubo otros grupos similares en muchos aspectos culturales a los Chachapoya. Uno de aquellos grupos humanos de importancia fue justamente el de Luya Chillao cuyos territorios comprendían...las actuales provincias de Luya y Utcubamba..." (Ruiz 2009a: 5). ${ }^{30}$

Como mencionamos anteriormente, el término genérico Chachapoya define un conjunto de subgrupos que formaban la "tradición" o la "cultura arqueológica" Chachapoya. Según Lerche (1995: 27) "no podría ser una autodeter-

28 Por ejemplo los vanos de acceso que presentan peldaños en forma semicircular (Gaither et al. 2008: 30).

29 La cerámica Chipuric o Kuelap Pintado Alisado constituye aproximadamente un $90 \%$ de la cerámica diagnóstica, encontrada durante los trabajos de prospección y excavación.

30 Los subrayados son de los autores del presente artículo. 


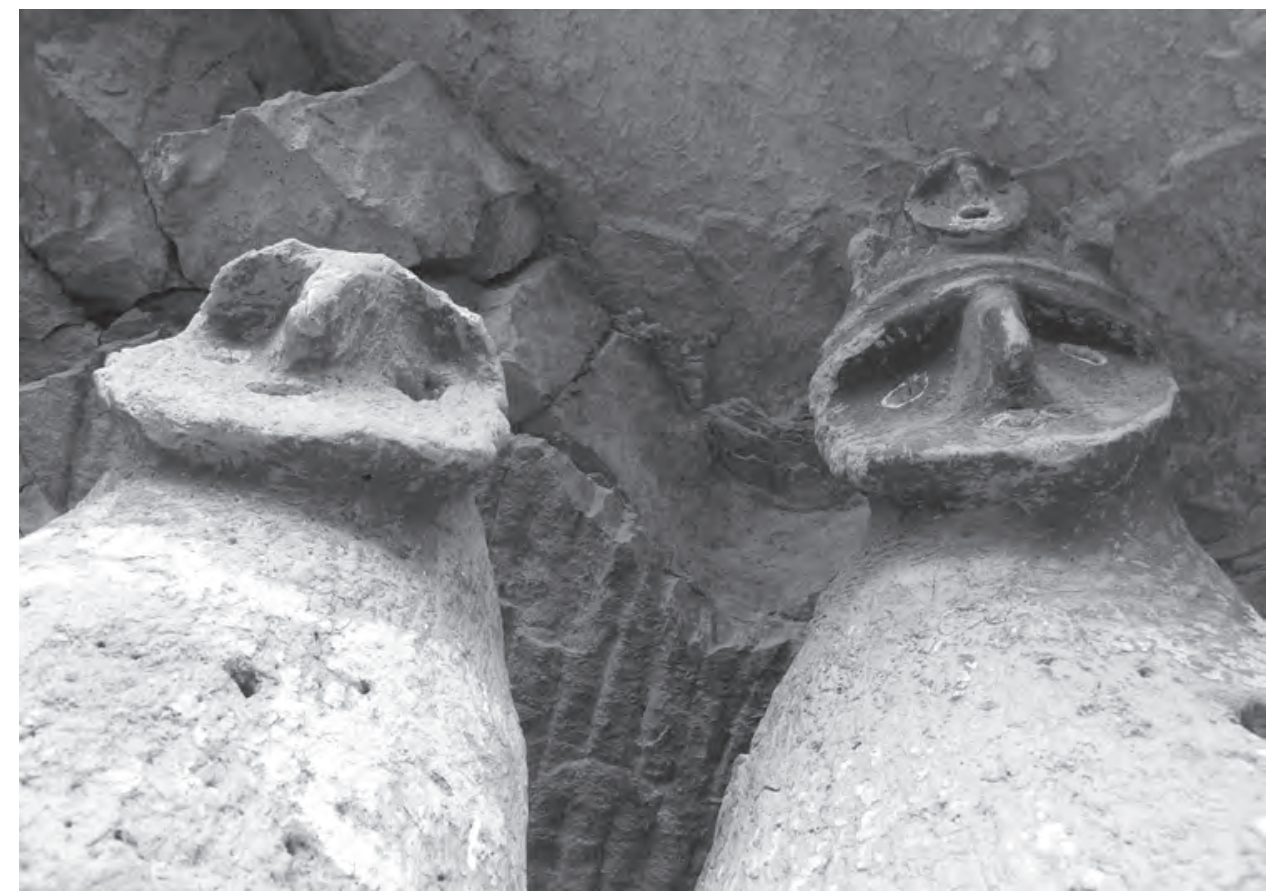

Figura 25. PAJ 83 - Sarcófagos (Foto: K. Koschmieder)

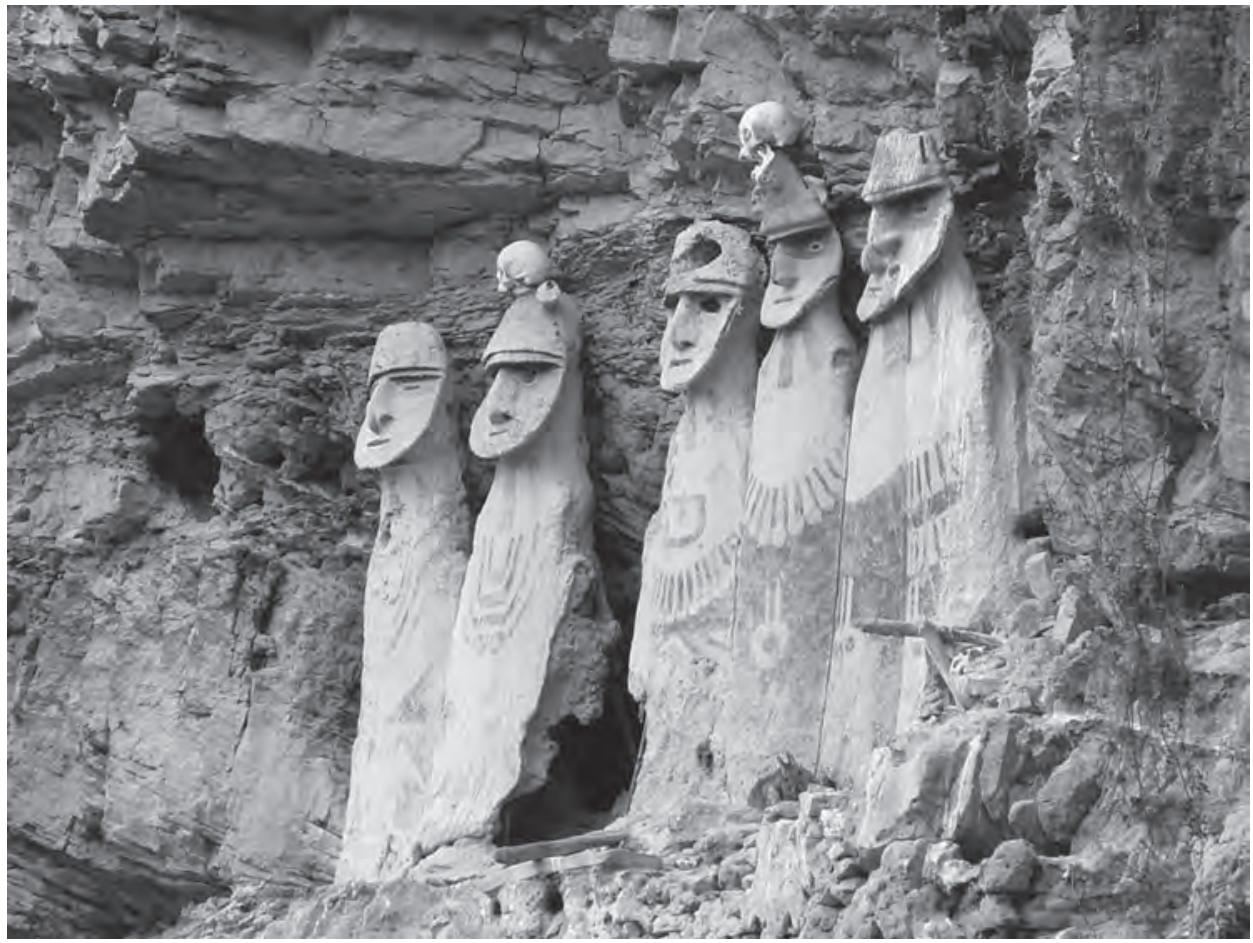

Figura 26. Karajía - Sarcófagos (Foto: K. Koschmieder) 
minación común de los grupos étnicos, perteneciendo a una familia lingüistica diferente". Por la necesidad administrativa, los Inca bautizaron a los diferentes subgrupos como "Chachapoya" (Lerche 1995: 27-28; Schjellerup 2005:59). El nombre Chacha, introducido por los Inca, aparece únicamente en relación con algunos moradores autóctonos de la zona de Levanto, pero en ningún momento existió un curacazgo o un subgrupo que se autodenominaba Chacha o Chachapoya (Lerche 1995: 28).

Algunos investigadores postulan que los denominados Chillaos ocuparon en tiempos prehispánicos una zona extensa que incluía la actual provincia de Luya, pero las informaciones que presentan Zevallos (1995) y Ruiz (2009 a) se remiten a la subdivisión política-administrativa de la zona durante el predominio de los españoles. En el período colonial temprano, la antigua provincia Inca de Chachapoyas estaba dividida en tres corregimientos: Caxamarquilla - Collai, Luya - Chillaos y Pacllas. Posteriormente se constituyó la provincia de Luya y Chillaos, que se componía de 19 repartimientos, los cuales reemplazaron los dos hunos incaicos "Atun Luya" y "Chilao" (Lerche 1986, 1995). La segmentación política española corresponde hasta cierto punto a la última revisión Inca de la división huno de la provincia. En un mapa de Martínez de Compañón (1789) la provincia de Luya y Chillaos atravieza la provincia de Chachapoyas (Schjellerup 2005: 58, Fig. 10), mientras en otro mapa, elaborado por Espinoza (1967: 333) en base a sus estudios de algunos documentos del siglo XVI, la "étnia" Chillaos poblaba la actual provincia de Utcubamba, es decir, una zona fuera de Luya.

El término Chillao(s) aparece en algunas crónicas españolas y describe un subgrupo de la tradición Chachapoya que se oponía a las incursiones inca(s) y españolas de sus territorios. Su área de distribución geográfica es desconocido y no se puede argumentar que este debe haber coincidido con los límites de la provincia española de Luya y Chillaos (y menos de la moderna provincia de Luya) o del antiguo corregimiento Luya y Chillaos, el cual en algún momento in- cluía algunas zonas de la selva alta, como el supuesto territorio de otro subgrupo Chachapoya, los Chilchos (Schjellerup 2005: 57). El mismo Zevallos (1995: 17-18) tiene dudas sobre la ubicación del territorio Chillao al decir "por ahora consideramos imposible deducir cual fue...su territorio...", pero mas adelante postula que "las gentes de los Chillaos debieron tener como centro...el área entre Lámud y Luya."

Las crónicas no mencionan el área geográfica que ocupaba la población Chillao, pero describen a los Chillaos como guerreros que apoyaron a las tropas de Huanca Auqui, el jefe militar de Huáscar, durante la guerra fraticida contra Atahualpa. Por otro lado, las demás poblaciones Chachapoya, bajo el mando de sus jefes Guamán y Zuta, ayudaron a los jefes militares de Atahualpa. En la denominada "batalla de Cochaguayllas" las tropas de Huáscar fueron derrotadas y miles de guerreros Chillao eliminados. Después del desastre de Cochaguayllas los vencidos y diezmados Chillao se retiraron a su tierra natal. (C. Valboa 1951 [1586]: 445, Espinoza 1967: 251-252; Sarmiento 1965 [1572]: 267) ${ }^{31}$

Durante la colonia hubo algunas sublevaciones de las poblaciones Chachapoya, una de éstas dirigida por los Chillao. Los españoles desarticularon la rebelión y ejecutaron al jefe Guayamamulos (Cieza 1987 [1553], III), el mismo que anteriormente hizo un pacto con Huáscar contra Atahualpa.

En la publicación "La gran historia del pueblo Chillao" (ADDK 2005) no se mencionan las derrotas de los Chillao ante las tropas incaicas y españolas. Más bien, se presentan datos sobre una supuesta resistencia exitosa de los Chillao frente a los españoles. Los autores afirman, que Kuelap fue la fortaleza de los Chillaos, el texto

31 Parece interesante que Sarmiento llamaba a los vencidos Chachapoya, como a todos los subgrupos, mientras los otros cronistas hablaban de Chillao(s) (Cieza 1985 [1553], II: 311; C. Valboa 1951 [1586]: 444-445), un indicio que la palabra Chachapoya fue utilizada como término genérico para describir a todas las poblaciones indígenas de la región. 
acompañado con un dibujo en el cual un supuesto Chillao pisa el cuerpo de un español frente a la fortaleza de Kuelap, sin reconocer que en el siglo XVI la fortaleza ya estuvo abandonada. Parece que el propósito del folleto es hacer resaltar la "cultura" Chillao. En la introducción los autores declaran:

"Los que poblamos el actual territorio de la provincia de Luya, descendemos de un pueblo forjador de una civilización avanzada... Por nuestras venas corre la sangre Chillao, una cultura indómita que se atrevió enfrentar la agresión de los imperios Inca y español. En este sentido, podriamos aseverar que los Chillaos no han desaparecido..." (ADDK 2005: 4-5).

La admiración del pasado prehispánico y la búsqueda de una identidad propia no debe llegar a tal extremo, incluyendo la falsificación o el invento de supuestos sucesos históricos.

Con los resultados de nuestro proyecto de investigación pretendemos esclarecer un poco la situación en la zona de Lámud-Luya durante el período prehispánico tardío, pero solamente con el aporte de fuentes históricas auténticas podriamos averiguar cuales fueron los (sub) grupos Chachapoya que poblaron las diferentes zonas durante la presencia Inca y española. Por el momento preferimos hablar de un "subgrupo Chachapoya" (en vez de llamarles Chillao o Luya) que pobló la zona de investigación y que enterró a su gente en una gran variedad de sitios funerarios, incluyendo sarcófagos antropomorfos y abrigos rocosos.

\section{Agradecimientos}

Agradecemos al Instituto Nacional de Cultura de Lima, especialmente a la Directora Cecilia Bákula Budge, por haber aprobado nuestro "Proyecto Arqueológico Jucusbamba" - Temporadas 2007 y 2009 (Resolución Directoral Nacional $\mathrm{N}^{\circ} 558$ del 3 de mayo del 2007 y Resolución Directora Nacional $N^{\circ} 1494$ del 24 de octubre del
2008). También a la entidad financiera del "Proyecto Arqueológico Jucusbamba", la "Deutsche Forschungsgemeinschaft" (Comunidad Alemana de Investigaciones).

Nuestra gratitud se hace extensiva a todos aquellos pobladores de Lámud y sus alrededores, quienes demostraron comprensión y facilitaron nuestra exploración. Además a los señores Orlando Poquis R., Juan Gupioc A., Javier Sinarahua S. y la señorita Roxana Mori U. (todos de Lámud) por ayudar en los trabajos de campo. Al igual agradecemos a los estudiantes Andersson Sernaqué C. (Universidad Nacional de Trujillo) y Jörg Schittenhelm (Universidad Libre de Berlin, Alemania) por su participación en los trabajos de excavación en los sitios PAJ 56-B y PAJ 113 (Lengache).

El material arqueológico fue analizado por Catherine Gaither (Óseo humano), Victor Vásquez S./Teresa Rosales T. (Óseo animal, restos vegetales y malacológico), Arabel Fernández L. (Textiles), Rodrigo Zuzunaga I. (Metales) y Milano Trejo M. (Flauta globular). El Sr. Felix Farro B. (Museo de Sechín, Casma) se dedicó a elaborar los dibujos de la cerámica diagnóstica y de la flauta globular. A todos ellos nuestro sincero agradecimiento. 


\section{BibLIOGRAFÍA}

ADDK (Asociación para la Defensa y Desarrollo de Kuelap)

2005 La Gran Historia del Pueblo Chillao. Cuadernos de Educación Alternativa.

Acosta, J. de

1954 [1590] Obras del Padre José de Acosta de la Compañia de Jesús. Biblioteca de Autores Españoles, Vol. 73, Edición Atlas, Madrid.

Aguilar, N.

1997 El Área Histórico-Cultural de Chillao y Luya, Lámud.

Agustinos, los primeros

1916 [1557] Relación de la Religión y Ritos del Perú... Colección de Libros y Documentos Referentes a la Historia del Perú, Tomo XI, pp. 3-56, Madrid.

Arriaga, P. J.

1951 [1586]La Extirpación de la Idolatría del Pirú. Edición facsimilar (Ed. H. Urteaga), Tomo I, Serie 2, Lima.

Bandelier, A.

1940 "Los Indios y las Ruinas Aborigenes cerca de Chachapoyas en el Norte del Perú." En Chaski, Vol. 1, No. 2, pp. 13. 59, Lima.

Bonavía, D. y R. Ravines

1967 "Las Fronteras Ecológicas de la Civilización Andina." En Amaru 2, pp. 61-69.

Bracamonte, $\mathrm{F}$.

2002 "Los Pinchudos: Un Estudio Preliminar de su Población." En Sian, Edición No. 12, pp. 14-15, Trujillo.

2004 "Los Pinchudos: Un Acercamiento a las Características Físicas de su Población." En Sian, Edición No. 15, pp. 18-19, Trujillo.

Briceño, J. y K. Muscutt

2004 "Fardos Funerarios Chachapoyas en la Laguna de Huayobamba." En Sian, Edición No. 15, pp. 6-7, Trujillo.

Cabello Valboa, M.

1951 [1586] Miscelánea Antartica. Instituto de Etnología. Universidad Nacional Mayor de San Marcos, Lima.

Calancha, A. de

1976 [1638] Corónica Moralizada del Orden de San Agustin. Prador Pastor, Lima.
Church, W.

1991 "La Ocupación Temprana del Gran Pajatén." En Revista del Museo de Arqueología, No. 2, pp. 7-38, Trujillo.

1994 "Early Occupation at Gran Pajatén, Perú." En Andean Past, No. 4, pp. 281318, Ithaca.

Cieza de León, P.

1984 [1553] Crónica del Perú. Primera Parte, PUCP, Lima.

1986 [1553] Crónica del Perú. Segunda Parte, PUCP, Lima.

1987 [1553] Crónica del Perú. Tercera Parte, PUCP, Lima.

Cobo, B.

1956 [1653] Obras del Padre Bernabé Cobo. Tomos I-II, Historia del Nuevo Mundo, Biblioteca de Autores Españoles, Madrid.

Espinoza S., W.

1967 "Los Señorios Étnicos de Chachapoyas y la Alianza Hispano-Chacha." En Revista Histórica 30, pp. 224-333, Lima.

Fabre, $\mathrm{O}$.

2008 "La Ocupación Prehispánica de las Cuevas del Departamento de Amazonas." En Boletin de Lima, Vol. XXX, No. 152, pp. 31-50, Lima.

Fabre, O., Loup, J., Salas, R., Malaver, M. y E. Maniero

2008 "Los Chachapoya de la Región de Soloco: Chaquil, del Sitio de Hábitat a la Cueva Funeraria." En Bulletin de L'Institut Francais d'Études Andines, Tome 37, No. 2, pp. 271-291, Lima.

Gaither, C., K. Koschmieder y G. Lombardi

2008 "En la Tierra de los Gigantes: Un Nuevo "Gigante" Encontrado en el Sitio NorAndino de Chichita, Perú." En Arqueobios, Vol. 2, pp. 28-39, Trujillo.

Garcilaso de la Vega, Inca

1965 [1609] Obras Completas. Biblioteca de Autores Españoles, Vol. II, Ediciones Atlas, Madrid.

Guamán Poma de Ayala, F.

1936 [1615] Nueva Corónica y Buen Gobierno. Edición Facsimilar. Travaux et Mémoirs de L'Ínstitut d'Ethnologie, No. 23, A. Metraux (ed.), Paris. 
Jacobsen, J., Jorgensen, J., Jorgensen, L. y I. Schjellerup

1986-87 "Cazadores de Cabezas en Sitios PreInca de Chachapoyas, Amazonas." En Revista del Museo Nacional 48, pp. 139. 185, Lima.

Karsten, R.

1935 The Head-Hunters of Western Amazon: The Life and Culture of the Jibaro of Eastern Ecuador and Perú. Helsingtors.

Kauffmann Doig, F. y. G. Ligabue

2003 Los Chachapoya(s) - Moradores Ancestrales de los Andes Amazónicos Peruanos. Universidad Alas Peruanas, Lima.

Koschmieder, K.

2008 Proyecto Arqueológico Jucusbamba. Informe presentado al Instituo Nacional de Cultura, Lima.

Koschmieder, K. y R. Paredes

2007 Proyecto Arqueológico Chichita. Informe presentado al Instituto Nacional de Cultura, Lima.

Langlois, L.

1934 "Conferencia - Las Ruinas de Cuelap." En: Boletin de la Sociedad Geográfica de Lima 51 (1), pp.20-34, Lima.

1939 Utcubamba. Imprenta del Museo Nacional, Lima.

Lecuanda, J.

1861 [1792] "Descripción Corográfica de la Provincia de Chachapoyas." En: Biblioteca Peruana de Historia, Ciencias y Literatura, M. Fuentes (ed.), Vol. I, pp. 221-235, Lima.

Lerche, $\mathrm{P}$.

1986 Häuptlingstum La Jalca - Bevölkerung und Ressourcen bei den Vorspanischen Chachapoya, Perú. Dietrich Reimer Verlag, Berlin.

1995 Los Chachapoya y los Símbolos de su Historia. Servicios Editoriales César Gayoso, Lima.

Lizárraga, R. de

1987 [1605] Descripción Breve de Toda la Tierra del Perú, Tucumán, Rio de la Plata y Chile. Madrid.

Middendorf, E.W.

1895 Perú - Beobachtungen und Studien über das Land und seine Bewohner während eines 25jährigen Aufenthalts, 3 Vol., Berlin.
Murúa, Fray M. de

2001 [1611] Historia General del Perú. Ed. M. Ballesteros Gaibrois, Crónicas de América.

Muscutt, K.

1998 Warriors of the Clouds - A Lost Civilization in the Upper Amazon of Perú. Albuquerque.

Narváez, A.

1988 "Kuélap: Una Ciudad Fortificada en los Andes Nororientales de Amazonas, Perú." En Arquitectura y Arqueología (CONCYTEC), pp. 115-142, Chiclayo.

1996a "La Fortaleza de Kuelap." En: Arkinka - Revista de Arquitectura, Diseño y Construcción, No. 12, pp. 92-109, Lima.

1996b "La Fortaleza de Kuelap." En Arkinka Revista de Arquitectura, Diseño y Construcción, No. 13, pp. 90-98 (Segunda Parte), Lima.

Nystrom, K.

2004 "Trauma e Identidad entre los Chachapoya." En Sian, Edición No. 15, pp. 20 21, Trujillo.

Pizarro, P.

1986 [1557] Relación del Descubrimiento y Conquista de los Reinos del Perú. PUCP, Lima.

Polo de Ondegardo, J.

1916 [1567] Instrucción Contra las Cermonias y Ritos que Usan los Indios Conforme al Tiempo de su Infidelidad. Colección de Libros y Documentos Referentes a la Historia del Perú, Serie I, Tomo III, pp. 189-203, Lima.

Ravines, R.

1972 "Los Caciques de Pausamarca: Algo más sobre las Etnias Chachapoyas." En Historia y Cultura, Vol. 6, pp. 217-247.

Reichlen, H.; P. Reichlen

1950 "Recherches Arqueológiques Dans les Andes de Haut Utcubamba." En Journal de la Societé des Americanistes 39, pp. 219-246, Paris.

Rivet, $\mathrm{P}$.

1949 "Les Langues de 1'Ancien Diocése de Trujillo." En Journal de la Societé des Américanistes. Nouvelles Série, T. XXXVIII, pp. 1-51. 
Ruiz Estrada, A.

1972 La Alfarería de Cuélap: Tradición y Cambio. Tesis de Bachillerato, Universidad Nacional Mayor de San Marcos, Lima.

1994 "La Cirurgía Prehispánica en el Departamento de Amazonas, Perú." En Sequilao 7, pp. 149-173.

2009a "Sobre las Formas de Sepultamiento Prehispánico en Kuelap, Amazonas.” En Arqueología y Sociedad, No. 20, Lima.

2009b "Las Pinturas Rupestres de Choclic." En Rupestreweb, <http://www.rupestreweb. info/choclic.html $>$.

Salinas Loyola, J. de

1965 [1571] "Cartas." En: Relaciones Geográficas de las Indias, Vol. III, p. 197, Madrid.

Sarmiento de Gamboa, P.

1965 [1572] Historia Indica. En Obras Completas. Biblioteca de Autores Españoles, Vol. II, Ediciones Atlas, Madrid.

Savoy, G.

1970 Antisuyo - The Search of the Lost Cities of the Amazon, New York.

Schjellerup, I.

2005 Incas y Españoles en la Conquista de los Chachapoya. PUCP y IFEA, Lima.

Shady, R.

1976 "Investigaciones Arqueológicas en la Cuenca del Utcubamba." En Actas del XLI Congreso Internacional de Americanistas, Vol. III, pp. 579-589, México.

1992 "Poblamiento Prehispánico de la Cuenca de Bagua - Jaén.” En Simposio Biodiversidad, Historia Cultural y Futuro del Parque Nacional Rio Abiseo, Resumen, p. 29, Lima.

Silva, $\mathrm{O}$.

2006 Civilizaciones Prehispánicas de América. Editorial Universitaria, Chile.
Taylor, G.

1996 La Tradición Oral Quechua de Chachapoyas. Travaux de 1'Institut Francais d'Études Andines, Vol. 95, IFEA, Lima.

Torero, A.

1989 "Áreas Toponímicas e Idiomas en la Sierra Norte Peruana. Un Trabajo de Recuperación Lingüistica”. En Revista Andina, No. 1, pp. 217-257, Lima.

Vázquez de Espinoza, A.

1948 [1626] Compendio y Descripción de las Indias Occidentales. Smithonian Miscellaneous Collection, Vol. 108, Washington.

Von Hagen, A.

2002 "Pueblo de las Nubes." En Chachapoyas - El Reino Perdido, pp. 25-261, Integra/ AFP, Lima.

2005 Los Chachapoya y la Laguna de los Cóndores. Museo Leymebamba.

Zetzsche, V. y K. Koschmieder

2010 "Im Reich der Wolkenkrieger" En Antike Welt, No. 1, pp. 35-42, Mainz.

Zevallos, J.

1982 [1966] "Onomástica Prehispánica de Chachapoyas" En Lenguaje y Ciencias, 20, pp. 27-44, Trujillo.

1995 "El Área Geográfico-Cultural de la Prehistoria de Chachapoyas. Una Nueva Postulación." En Gaceta Arqueológica Andina, No. 24, pp. 13-23, Lima.

Zubiate, $\mathrm{V}$.

1984 Guia Arqueológica del Departamento de Amazonas, Chachapoyas. 